\title{
Mechanical Models, Structures, and Applications of Shape-Memory Polymers and Their Composites
}

\author{
Xiaozhou Xin ${ }^{1} \quad$ Liwu Liu ${ }^{1 \star} \quad$ Yanju Liu ${ }^{1} \quad$ Jinsong Leng ${ }^{2 \star}$ \\ $\left({ }^{1}\right.$ Department of Astronautical Science and Mechanics, Harbin Institute of Technology (HIT), P.O. Box 301, \\ No. 92 West Dazhi Street, Harbin 150001, China) \\ $\left({ }^{2}\right.$ Centre for Composite Materials, Harbin Institute of Technology (HIT), P.O. Box 3011, No. 2 Yikuang \\ Street, Harbin 150080, China)
}

Received 29 January 2019; revision received 18 March 2019; Accepted 9 April 2019;

published online 19 June 2019

(C) The Author(s) 2019

\begin{abstract}
Shape-memory polymers (SMPs) and their composite materials are stimuliresponsive materials that have the unique characteristics of lightweight, large deformation, variable stiffness, and biocompatibility. This paper reviews the research status of the mechanical models for SMPs, shape-memory nanocomposites and shape-memory polymer composites (SMPCs); it also introduces some spatially deployable structures, such as hinges, beams, and antennae based on SMPCs. In addition, the deformation types of 4D printing structures and the potential applications of this technology in robots and medical devices are also summarized.
\end{abstract}

KEY WORDS Shape-memory polymers and their composites, Constitutive model, Deployable structure, $4 \mathrm{D}$ printing

\section{Introduction}

Shape-memory polymers (SMPs) are stimuli-responsive materials with the ability to maintain a temporary shape and return to the original shape under external stimuli (e.g., heat, electricity, light, magnetism, radio frequency, etc.) [1-7]. Shape memory effect (SME) is an intrinsic property of polymer materials, but different polymers with different molecular structures and components exhibit varying degrees of shape-memory properties [2]. Various SMPs with excellent SME have been developed, such as shape-memory epoxy [8-10], shape-memory cyanate [11], shape-memory styrene [12], shape-memory polyurethane [1], and shape-memory polycaprolactone [13]. A series of SMPs with dual-, triple- or multi-SMEs have also been developed. According to the external induction method, SMPs can be divided into thermal-sensitive, light-induced, electroactive, PH-sensitive, and magnetic-induced ones.

The shape-memory process of thermal-sensitive SMPs is divided into the following four stages (as shown in Fig. 1) [1-3, 14]: (1) heating and shaping: the sample is deformed into a temporary shape under external load after heated to above the switch temperature $\left(T_{\mathrm{SW}}\right) ;(2)$ cooling and fixing: with the external load maintained and the temperature lowered down to below $T_{\mathrm{SW}}$, the SMP sample "remembers" the temporary shape, and then it is unload; (3) reheating: the SMP sample is reheated to above $T_{\mathrm{SW}}$ and recovers from the temporary shape to the original shape. The detailed shape-memory mechanism of SMPs is explained using the viscoelastic theory and phase change theory in Sect. 2.

\footnotetext{
* Corresponding authors. E-mails:liuliwu_006@163.com; lengjs@hit.edu.cn
} 


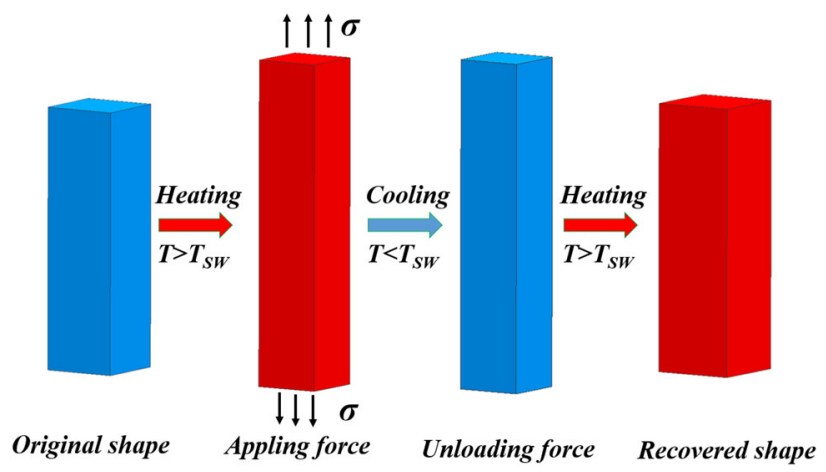

Fig. 1. The shape-memory recovery process of typical thermally actuated SMPs (red color indicates higher temperature of the material than $T_{S W}$, and blue color indicates lower temperature of the material than $T_{S W}$ ). (Colour figure online)

From the phase level, SMPs consist of at least a stable molecular network and a second phase [4]. The stable network is achieved through chemical cross-linking, crystallization and interpenetrating networks, providing SMPs with the resilience to maintain a permanent shape. The second phase can fix the temporary shape by glass transition, crystallization, transition between different liquid crystalline phases, etc. There are three important transition temperatures for thermal-sensitive SMPs: glass transition temperature $\left(T_{\mathrm{g}}\right)$, melting temperature $\left(T_{\mathrm{m}}\right)$, and isotropic temperature $\left(T_{\mathrm{i}}\right)$. Glass transition can be used to describe chemically cross-linked thermoset materials and physically cross-linked thermoplastic polymers. Melting transition can be used to describe semicrystalline polymer networks and chemically cross-linked rubbers, etc. Since the $T_{\mathrm{g}}$ of $T_{\mathrm{m}}$-based SMPs is much lower than room temperature, $T_{\mathrm{m}}$ is used as the $T_{\mathrm{SW}}$ in SME. $T_{\mathrm{i}}$ is used to describe the $T_{\mathrm{SW}}$ of liquid crystalline SMPs. Phase transitions of liquid crystal elastomers (LCEs) from anisotropic phase to isotropic phase have SME by introducing chemical or physical cross-links. The reversible change in the orientation of $T_{\mathrm{i}}$-based SMPs causes the polymer to form a reversible shape change or dual SME. It is worth noting here that due to the existence of second-order phase transitions, the shape-memory recovery response of $T_{\mathrm{g}}$-based SMPs is slower than that of $T_{\mathrm{m}}$-based SMPs, which makes it useful in structures that require slow deployment, such as space-deployable structures (see Sect. 3 for details).

However, the application of SMPs is restricted by their low driving force and obvious thermoviscoelasticity, leading to the emergence of shape-memory polymer composites (SMPCs) [3]. The shape-memory nanocomposites (SMPNs)/SMPCs can greatly improve mechanical properties [2], which are prepared by mixing SMPs with the zero-dimensional (nanoparticles: $\mathrm{Fe}_{3} \mathrm{O}_{4}$, etc.), one-dimensional (short fiber, continuous unidirectional fiber, CNT, etc.) or two-dimensional (fiber fabric, nano-paper, etc.) material as a reinforcing phase. The reasonably enhanced phase volume fraction not only improves the mechanical and thermomechanical properties of SMPs, but also enriches the driving methods such as electricity [15-18], magnetism [19, 20], light [21, 22], radio frequency (RF) [23, 24], etc. Shapememory polymers and their composites have many advantages, such as high malleability, highly adjustable transition temperature, various driving methods, low impact during deployment, and biocompatibility. All of these properties have potential applications in a wide range of fields including aerospace, flexible electronics, and bioengineering [23-28].

The paper is organized as follows: Sect. 2 presents the prediction of the mechanical properties of SMPs/SMPCs. Section 3 reviews the application of SMPs/SMPCs in aerospace and 4D printing.

\section{Prediction of Mechanical Properties of SMPs/SMPCs}

The mechanism of shape-memory cycles and the mechanical behavior of SMPs can be described by establishing thermomechanical models, which lay the theoretical foundations for the rational design of SMP structures. This section will focus on the constitutive models for SMPs, the micromechanical models of SMPNs, and the buckling behavior of SMPCs. 


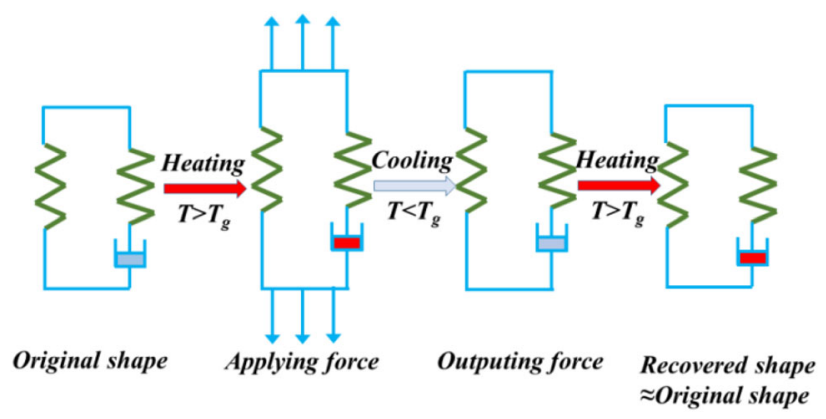

Fig. 2. SLS model (blue dashpot represents the maximum viscosity of SMPs, and red dashpot represents the minimum). (Colour figure online)

\subsection{Constitutive Models of SMPs}

In order to investigate the deformation behavior and shape-memory cycle mechanism of SMPs, a series of constitutive models have been developed to describe the complex thermoviscoelastic behavior of the material. Currently, there are three types of SMP constitutive models [2]: 1. the rheological method based on theory of viscoelasticity; 2. the phase transformation theory, which elaborates the thermomechanical behavior of SMPs from the mesoscopic level; 3. the combination theory, which combines the two aforementioned models.

\section{(1) Theory of Viscoelasticity}

The standard linear solid (SLS) model can briefly describe the shape-memory behavior (SMB) of $T_{\mathrm{g}}$-based SMPs. The viscosity of the dashpot decreases, and the SMP is deformed to the desired shape under an external load when the SMP is heated to above $T_{\mathrm{g}}$. The SMP can "remember" its original shape after unloading, which is due to the increase in viscosity as temperature decreases. After reheating, the viscosity decreases and the SMP recovers to its original shape (as shown in Fig. 2). Although the above model briefly describes the thermomechanical cycle process, the SMB of SMPs is strongly associated with strain, time, temperature, strain rate, and other factors, which requires a more complex constitutive model.

Some reported viscoelastic constitutive models and equations are summarized in Table 1. Tobushi et al. introduced a slip element based on SLS to describe the internal friction and thermal expansion behavior of shape-memory polyurethanes (SMPUs) and developed linear and nonlinear 1D constitutive models [29-31]. Chen's model explained how the reversible phase of SMPU could fix its temporary shapes without external loads, and how its fixed phase could remember its original shape [32]. Khonakdar et al. investigated the SMB of SMPUs using the Kelvin element in series with the dashpot $[33,34]$. Diani et al. proposed a 3D constitutive model for epoxy SMPs for first time. Although this model explained the stress-strain-temperature behavior of polymers during the thermomechanical loading process, it fell short in accounting for a number of details [35]. Nguyen et al. combined the Adam-Gibbs nonlinear structure relaxation model and the modified Eyring model into the thermoviscoelastic framework. This model provided a more accurate explanation of the effect of heating/cooling rate on the SMB [36]. Srivastava et al. established a thermomechanical coupled large deformation constitutive model to describe the intermolecular and molecular network resistance of amorphous SMPs through microstructural theory [37, 38]. In addition, they numerically analyzed the shape-memory response of the stent. In order to explain the dependence of SMB on time and temperature more clearly, Yu et al. paralleled the elastic spring with multiple Maxwell models to describe the equilibrium and non-equilibrium behavior of the polymer. They also predicted the static and dynamic mechanical properties and cyclic loading behavior of the material [39, 40].

$\mathrm{Gu}$ et al. used the modified argon scalar equation and the Eyring model to characterize the temperature-dependent and stress-activated properties of polymers and combined them with the structural and stress relaxation to describe the finite deformation behavior of thermally induced amorphous SMPs. The numerical prediction results indicated that the starting temperature of strain recovery 


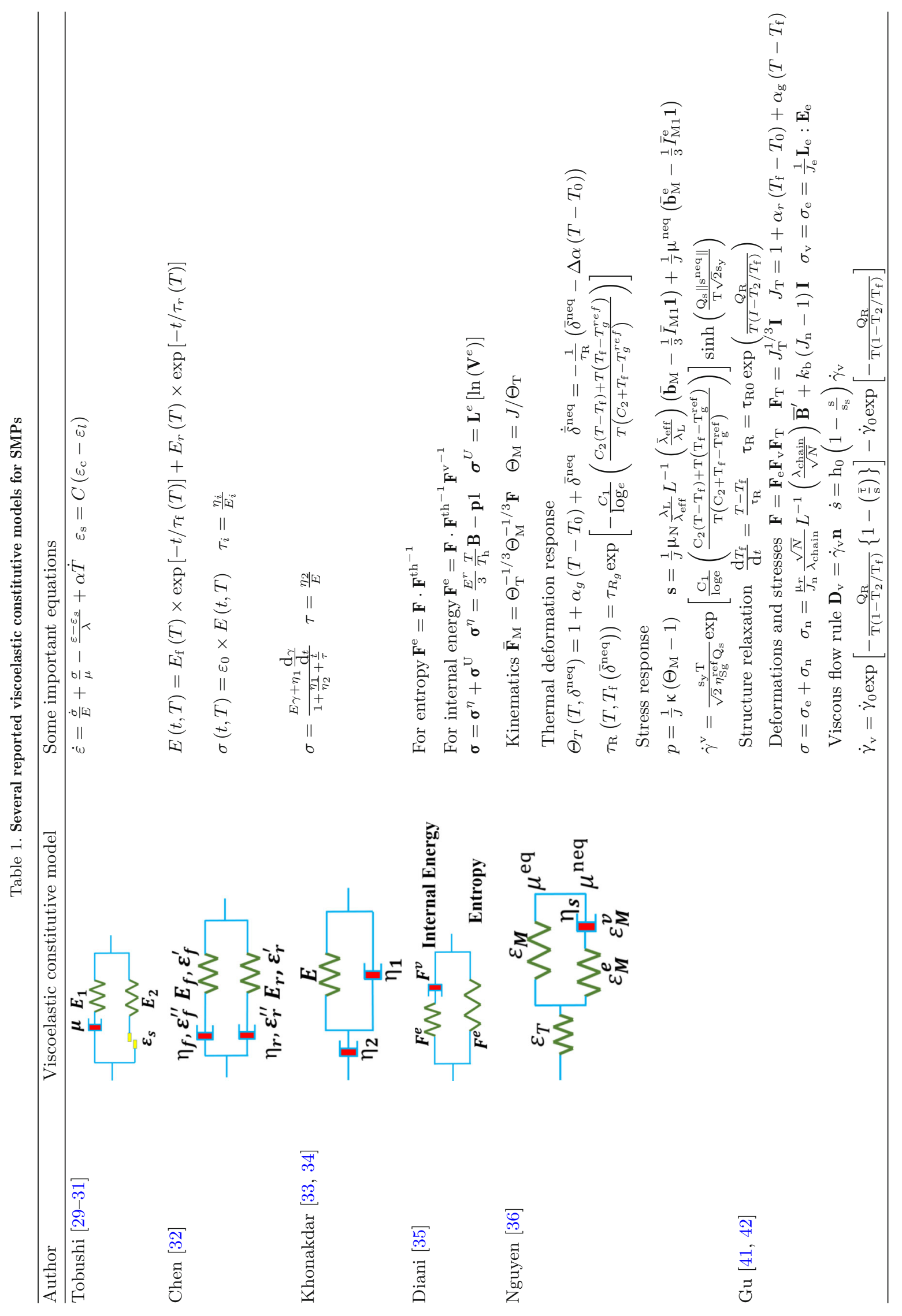


Vol. 32, No. 5

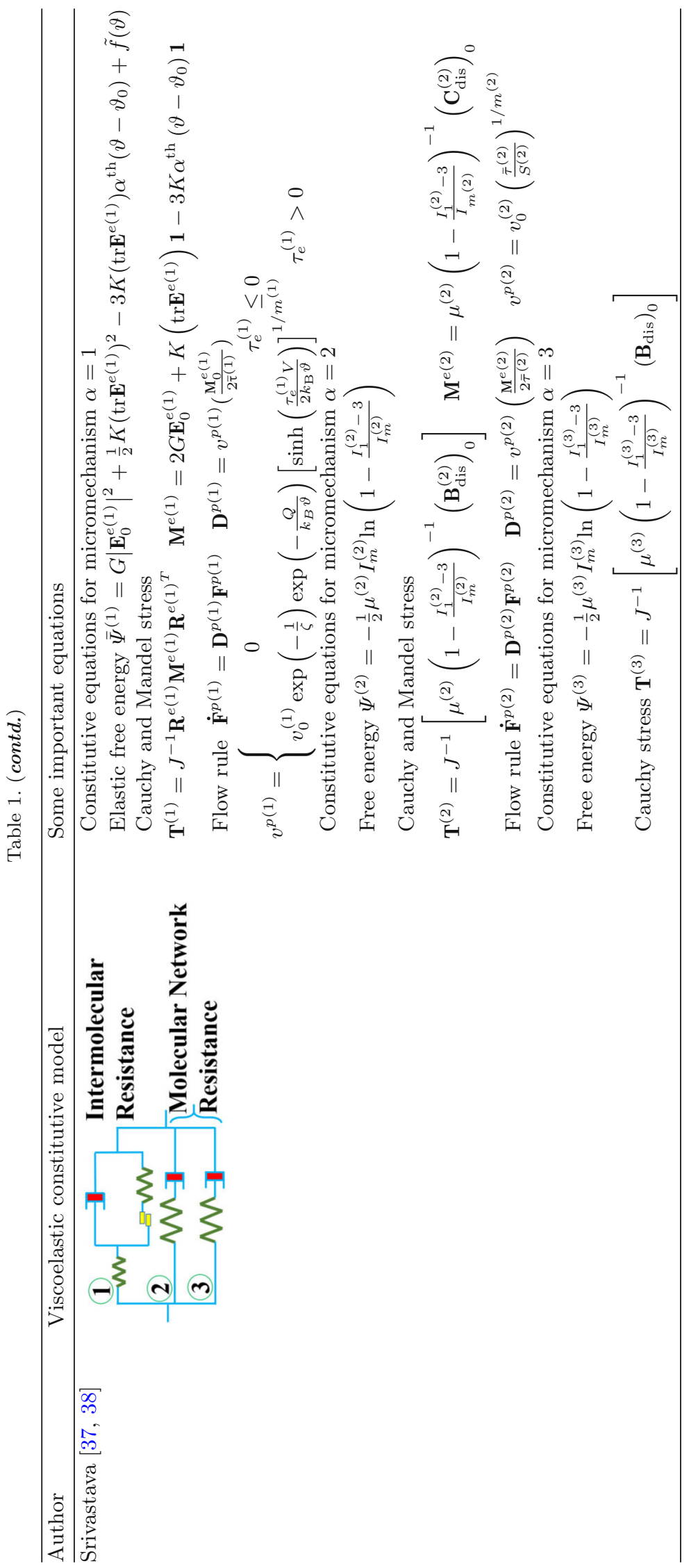




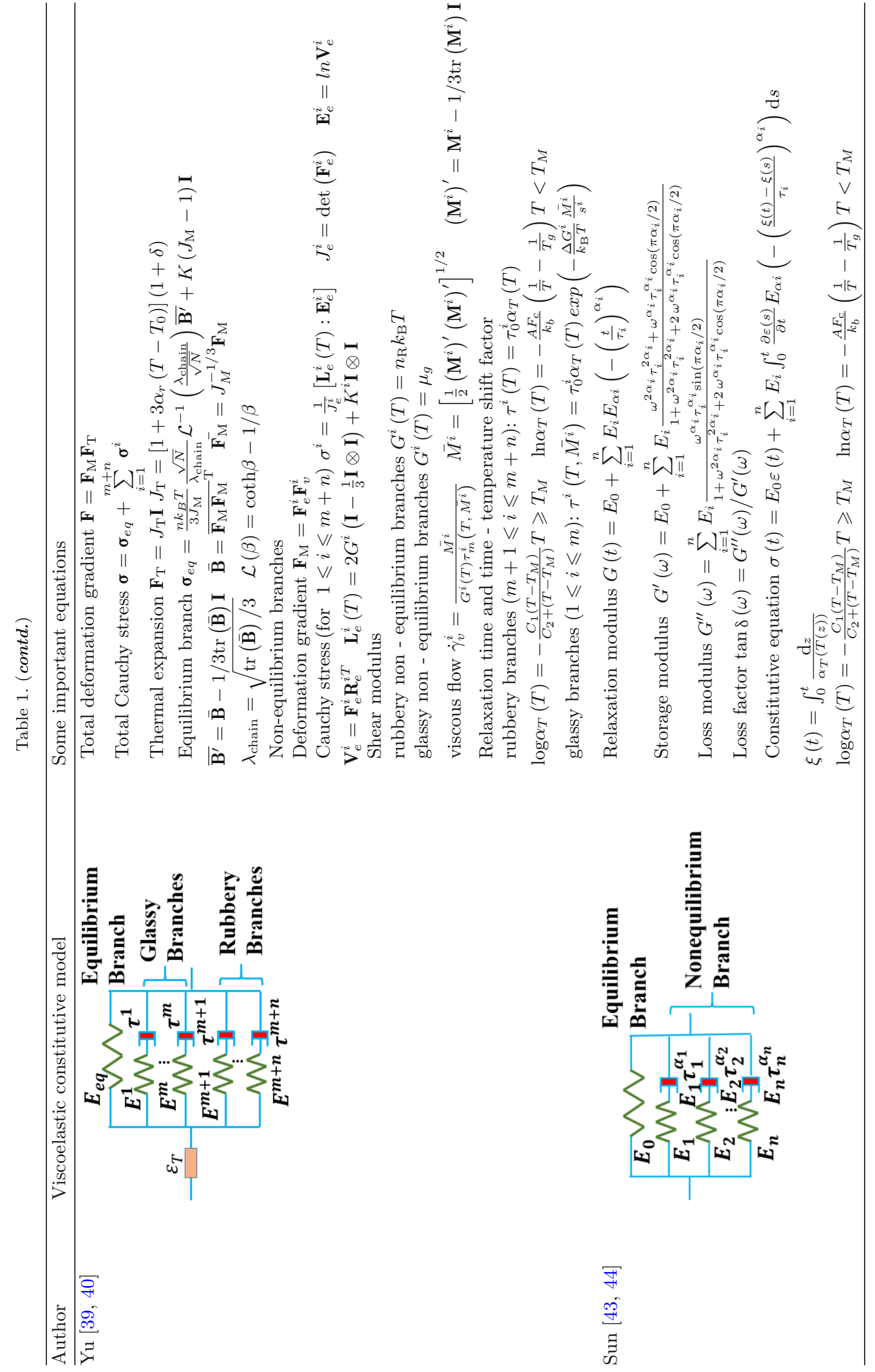




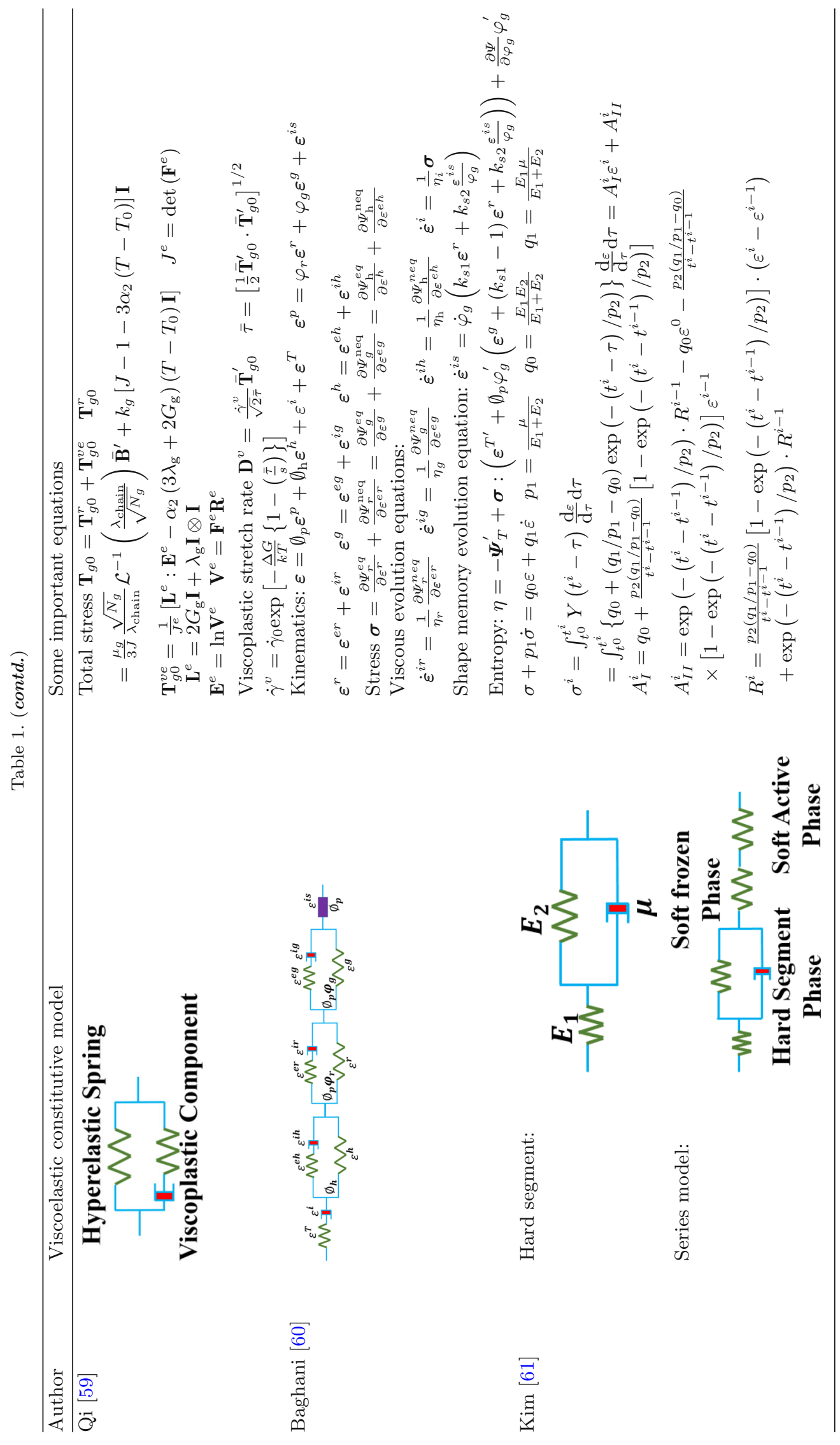




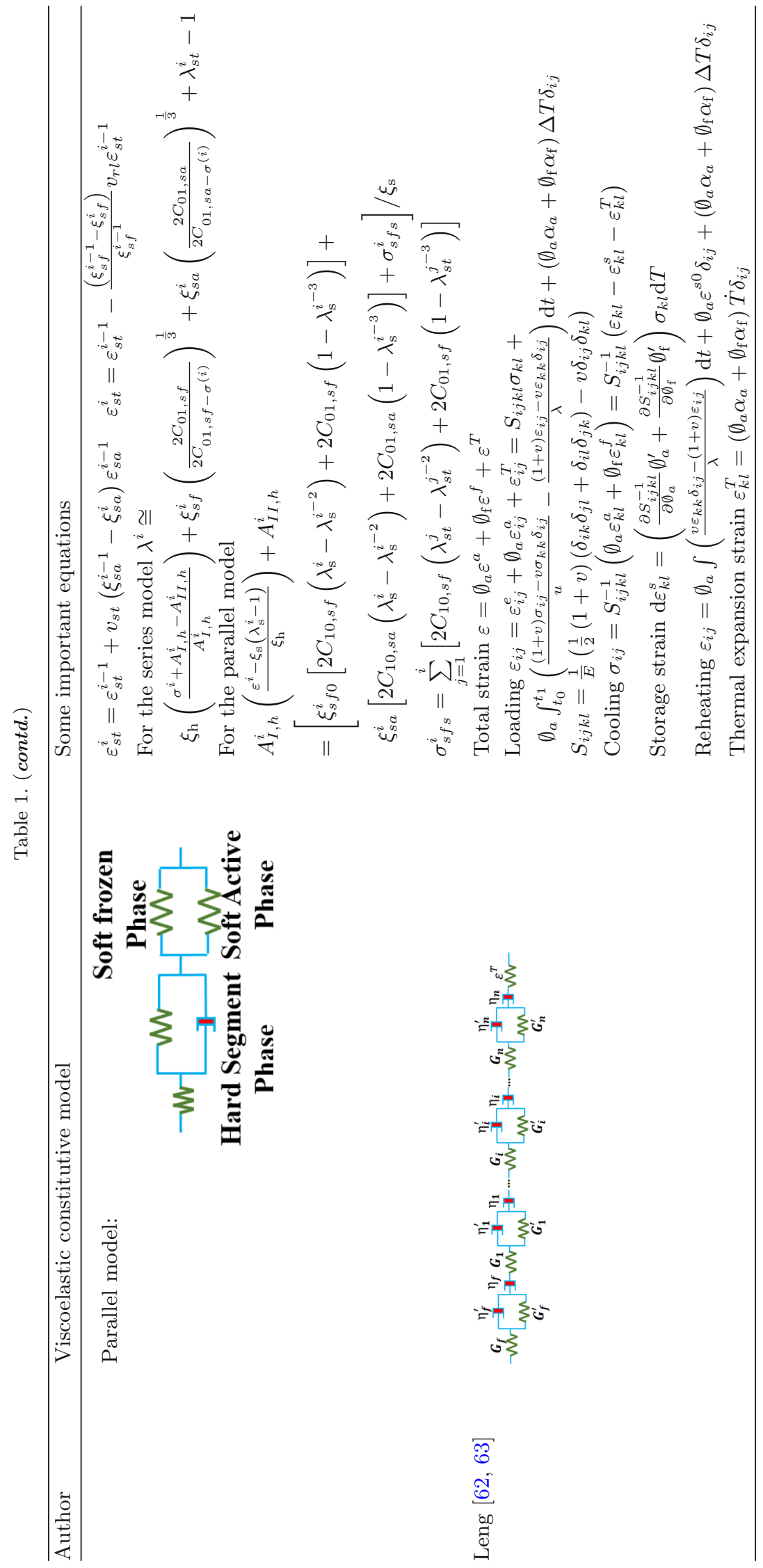




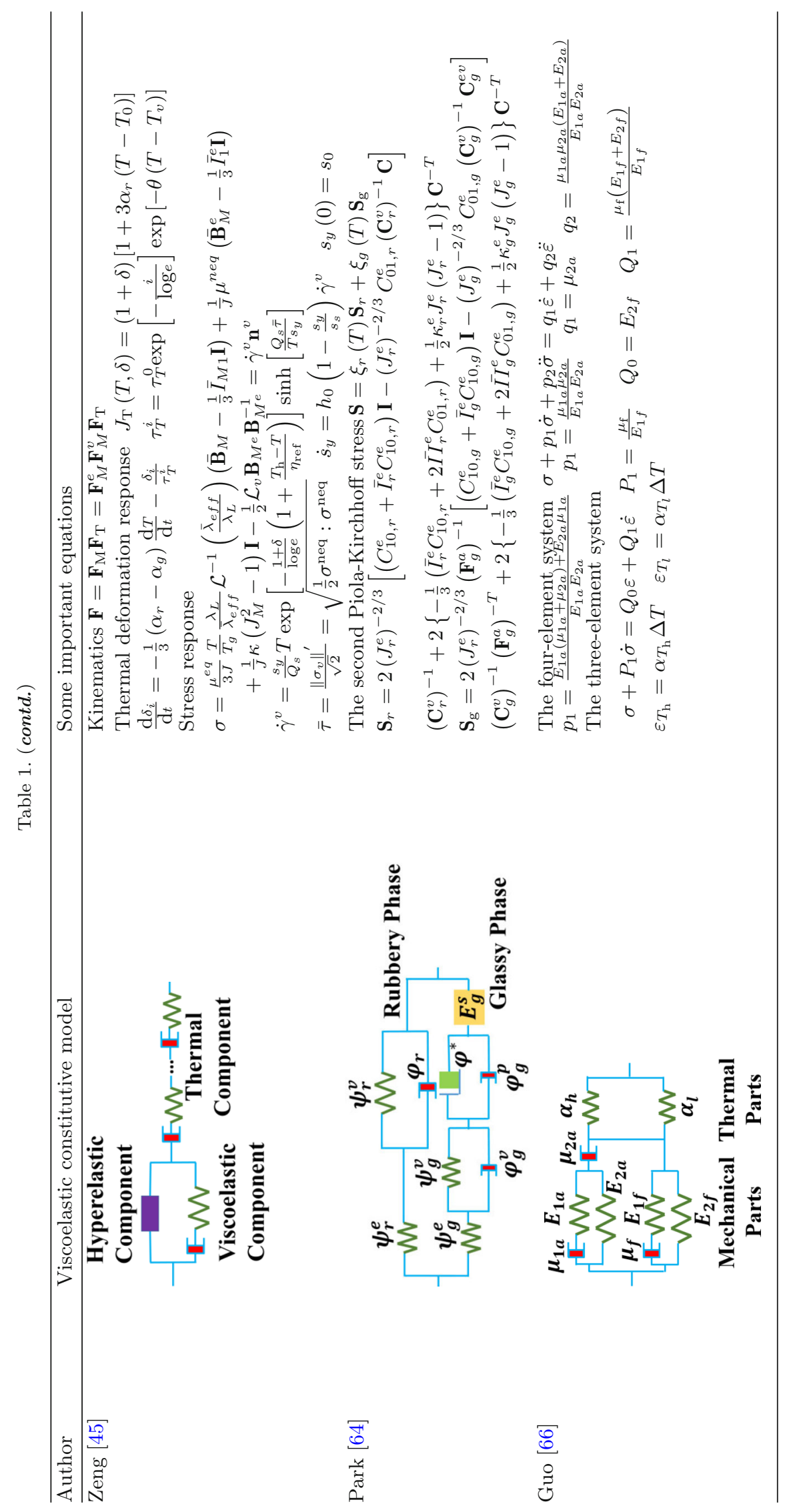




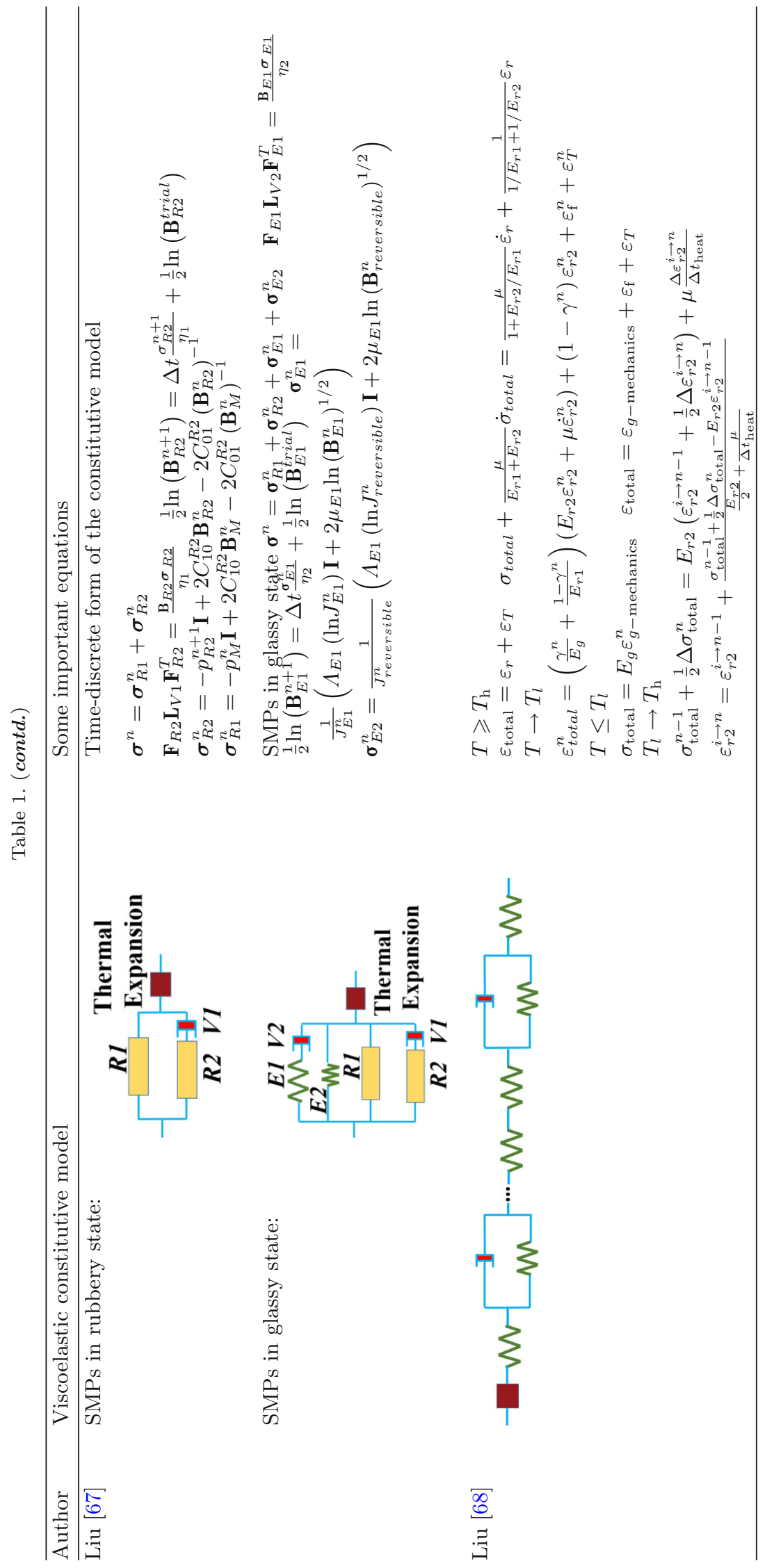


Table 2. Expressions of frozen phase volume fraction

\begin{tabular}{|c|c|}
\hline Author & Expression of Frozen phase volume fraction \\
\hline Liu [46] & $\varphi(T)=1-\frac{1}{1+c_{\mathrm{f}}\left(T_{\mathrm{h}}-T\right)^{n}}$ \\
\hline Wang [49] & $\varphi(T)=\alpha \exp \left(-\left(\frac{T_{t}}{T}\right)^{m} \beta^{n}\right)$ \\
\hline Reese [50] & $\varphi(T)=\frac{1}{1+\exp \left(\frac{2 w}{T-T_{\mathrm{t}}}\right)}$ \\
\hline Volk [51-54] & $\varphi(T)=\frac{\tanh \left(\frac{T_{\max }-A}{B}\right)-\tanh \left(\frac{T-A}{B}\right)}{\tanh \left(\frac{T_{\max }-A}{B}\right)-\tanh \left(\frac{T_{\min }-A}{B}\right)}$ \\
\hline Gilormini [55] & $\varphi(T)=\left[1-\left(\frac{T-T_{\min }}{T_{\max }-T_{\min }}\right)^{m}\right]^{n}$ \\
\hline $\mathrm{Li}[56]$ & $\varphi(T, \dot{T})=1-\int_{r_{\mathrm{c}}(T)}^{\infty} p(r) \mathrm{d} r \times\left\{1-\left[1-\exp \left(-\frac{\Delta H_{a}(T)}{k_{\mathrm{B}} T}\right)\right]^{\frac{\Delta t}{\tau_{0}}}\right\}$ \\
\hline Qi [59] Liu [68] & $\varphi(T)=\frac{1}{1+\exp \left(-\frac{\left(T-T_{t}\right)}{A}\right)}$ \\
\hline $\operatorname{Kim}[61]$ & $\varphi_{\text {sfo }}=\varphi_{\text {sf }}-\int_{t} \frac{\mathrm{d} \varphi_{\text {sa }}}{\mathrm{d} t} \mathrm{~d} t$ \\
\hline Leng $[62,63]$ & $\varphi(T)=\int_{T_{\mathrm{S}}}^{T} \frac{1}{S \sqrt{2 \pi}} \exp \left(-\frac{T-T_{\mathrm{g}}}{2 S^{2}}\right) \mathrm{d} T$ \\
\hline Park [64] & $\varphi_{\mathrm{g}}=\left\{\begin{array}{l}1 \quad 1<\varphi_{\mathrm{g}}^{0} \\
\varphi_{\mathrm{g}}^{0} 0 \leq \varphi_{\mathrm{g}}^{0} \leq 1 \quad \varphi_{\mathrm{g}}^{0}=\frac{b}{1+\exp \left(c\left(T-T_{\mathrm{tr}}\right)\right)}-d \\
0 \quad \varphi_{\mathrm{g}}^{0}<0\end{array}\right.$ \\
\hline Guo $[66]$ & $1-\varphi_{\mathrm{f}}=\varphi \exp \left(-\left(k T_{\operatorname{tran}} /(T-\tau \beta)\right)^{m} / \beta^{n}\right)$ \\
\hline Liu [57] & $\varphi(T, \dot{T})=1-\frac{1}{1+\exp \left\{-\left[T-T_{\operatorname{tr}}(\dot{T}) / b\right]\right\}}$ \\
\hline $\mathrm{Lu}[58]$ & $\varphi_{\mathrm{f}}=1-\gamma=1-A T \exp \left(-\frac{\Delta G\left(T_{\mathrm{h}}\right) 10^{-\frac{C_{1}\left(T-T_{\mathrm{h}}\right)}{C_{2}+T-T_{\mathrm{h}}}}}{R T}+\frac{T_{\mathrm{h}}-T}{b \cdot T_{\mathrm{h}}-T}\right)$ \\
\hline
\end{tabular}

of SMPs increases with the heating rate, but the slopes of the recovery rate-temperature curves are basically the same at different heating rates [41, 42]. Sun et al. developed a model with a significantly reduced number of parameters compared to the multi-branch models containing integer-order derivatives based on the multi-branch model of fractional derivatives. In addition, the model can also be used to predict the free recovery behavior of triple- and multi-SMEs and foams [43]. Zeng et al. proposed a rate-dependent yield factor to modify the Eying model and combined it with the multi-branch fractional derivative thermoelastic model to describe the temperature-dependent, strain-rate-dependent, yield and post-yield behavior of SMPs [44]. Subsequently, Zeng et al. also developed a new thermoelastic constitutive model by introducing internal variables and uncoupled relaxation mechanisms, which introduced a more explicit physical description of the structural and stress relaxation of the polymer [45].

(2) The phase transformation theory

The phase transition theory explains the shape-memory mechanism from the mesoscopic level, which first explains the SME mechanism of shape-memory alloy (SMA) through martensite and austenite transformation [2]. Table 2 summarizes the equations for important parameters of the phase transition theory (the frozen phase volume fraction).

Liu et al. first used this theory to describe the SMB of SMP and suggested that SMP consists of two phases: the frozen phase (glassy state) and the active phase (rubbery state) (as shown in Fig. 3). The ratio between the two phases is regulated by introducing a frozen phase volume fraction, $\varphi(T)(0 \leqslant \varphi \leqslant 1)$. In this equation, when the material is at a low temperature $\left(T_{1}<T_{\mathrm{g}}\right), \varphi\left(T_{1}\right)=1$, when it is at a high temperature $\left(T_{\mathrm{h}}>T_{\mathrm{g}}\right), \varphi\left(T_{\mathrm{h}}\right)=0$. They also introduced the concept of "stored strain" to describe the storage and release of strains [46]. Chen et al. established a constitutive model capable of describing the hyperelastic behavior of SMPs more clearly [47, 48].

Experiments have found that SMPs are rate dependent during the freezing process. For example, when the equivalent frozen phase volume fraction is reached, the non-isothermal cooling will attain a 


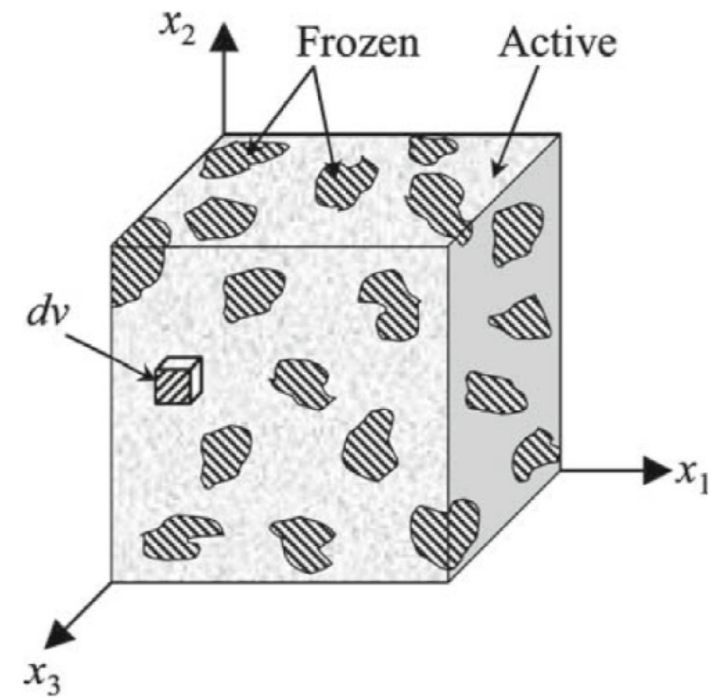

Fig. 3. Schematic diagram of microscopic mechanics of 3D constitutive model of SMPs [46]

lower temperature than the isothermal cooling. In addition, considering the large difference of Young's modulus between the frozen and active states, the mixing law cannot accurately predict the equivalent modulus of SMPs. Wang et al. proposed a time- and temperature-dependent constitutive model to solve the above problems by constructing a rate-dependent expression of frozen volume fraction [49]. Reese et al. proposed a new expression of frozen phase volume fraction and performed finite element prediction on the SMP stent [50]. Volk et al. investigated the thermomechanical properties of SMPs and derived the phenomenological 3D constitutive model under finite deformation. However, this model was unable to predict the unrecoverable strain [51-54]. Gilormini et al. also proposed a new expression of frozen phase volume fraction and constructed a phase change constitutive model based on micromechanics [55]. Li et al. proposed the evolution law of phase transition from a physics perspective [56]. The frozen phase was regarded as the matrix and the inclusion as the active phase. The equivalent mechanical properties of SMPs were predicted by Mori-Tanaka theory.

Considering the influence of heating/cooling rate, a new constitutive model for predicting the mechanical response of different SMPs at different recovery conditions (free recovery, fixed-stress recovery, and different heating rates) was proposed by Liu [57]. Lu et al. proposed a physically significant phenomenological model of "frozen volume" caused by internal stress and dominated by the two-site model theory. Compared with other models based on phase transformation, predicting the thermomechanical behavior of SMPs by using internal stress parameters is the most important feature of Lu's model [58].

(3) The combination theory

Although the rheological theory can adequately explain the behavior of stress relaxation, the interpretation of strain storage and strain release of materials is not as clear as the phase transition theory. In addition, the time-temperature equivalence of polymers cannot be satisfactorily considered by the phase transition theory. The combination of phase transformation theory and viscoelasticity theory not only explains the viscoelasticity and rate dependence of the polymer, but also physically relates the SME to the glass transition.

Qi et al. proposed three-phase-transition constitutive models, including the rubbery phase (RP), frozen glassy phase (FGP), and initial glassy phase (IGP). The RP appears above $T_{\mathrm{g}}$; FGP represents the new glassy phase of RP conversion caused by cooling; IGP represents the glassy phase in the initial state [59]. Baghani et al. fully considered the viscous effect of the material and proposed a smallstrain 3D constitutive model under time-dependent thermomechanical loading form and verified its accuracy [60]. Kim et al. constructed a three-phase phenomenological constitutive model based on the 


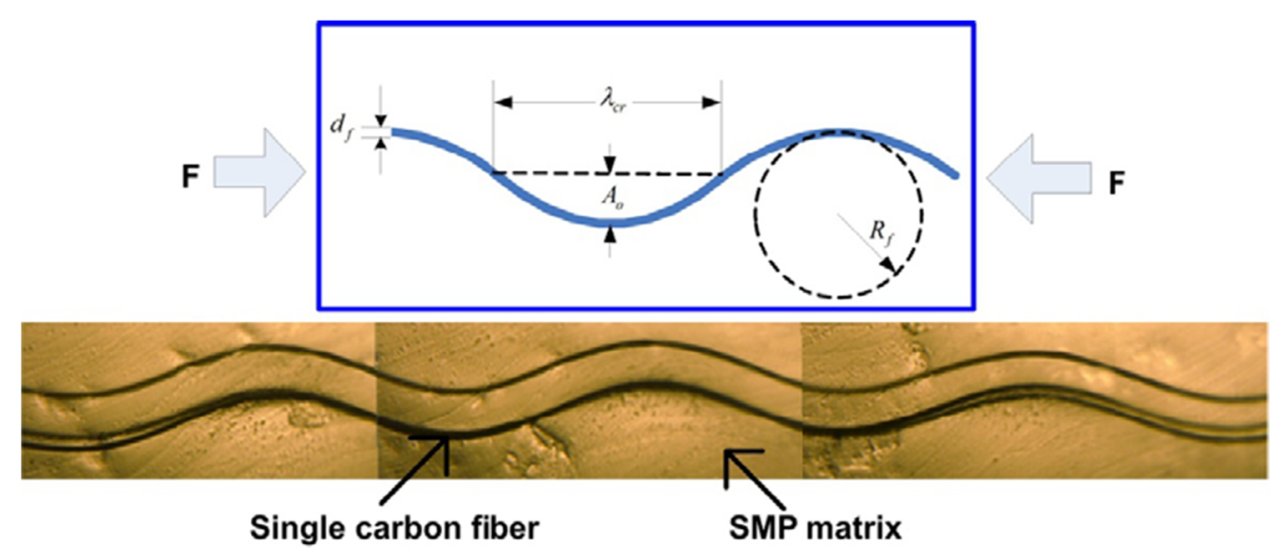

Fig. 4. Micro-buckling of SMPCs under compressive load [87]

molecular configuration of the hard and soft segments of SMPUs. In this constitutive model, a threeunit viscoelastic model was used to describe the hard-segment phase; and the Mooney-Rivlin model was used to describe the active and frozen soft segments [61]. Leng et al. established a new constitutive model based on viscoelastic theory and phase transition theory. In addition, a normal distribution model with fewer parameters and reasonable physical meaning was proposed [62,63]. Based on the assumption that shape memory strain is proportional to total deformation, Park et al. decomposed the total deformation gradient multiplication into hyperelasticity, viscoelasticity, viscoplasticity, and shape memory strain to establish a constitutive model that can describe multi-axial loading and large deformation (up to $200 \%$ strain) [64].

In the process of heating/cooling, the temperature transfer of the polymer is from the surface to the inside; similarly, the phase transformation of the material should also be carried out gradually from the surface to the inside. However, it is unreasonable to assume that the frozen phase and the active phase are evenly distributed in the polymer based on the microstructures of particle-reinforced composites [46] and unidirectional fiber-reinforced polymer composites [65], and the phase transition between the two phases (end/start) at the same time. Therefore, Guo et al. considered the microstructure of a semicrystalline SMP to propose a novel microstructure consisting of an active phase with a constant network and a frozen phase that can be switched between the free state and the frozen state [66]. A novel type of frozen phase transformation equation is shown in Table 2.

In view of the fact that many constitutive models developed in previous work were only based on specific materials, Liu et al. established a constitutive model based on the multiplicative decomposition of deformation gradient, which can describe large deformation of different types of SMPs. This model considers that the occurrence of phase transition is caused by the sudden formation and disappearance of reversible phase, but the phase transition should be from one phase to another [67]. Subsequently, Liu et al. further established a new constitutive model capable of degenerating into pure elasticity when the viscosity of the material is neglected [68].

\subsection{Prediction of Mechanical Properties of SMPCs}

The static or quasi-static mechanical properties, such as stiffness and strength, are mainly considered for conventional resin-matrix composites. However, for shape-memory polymers and their composites, the dynamic mechanical properties of materials such as driving and deformation are mainly considered. Accurate and effective prediction of the thermomechanical properties of SMPCs can provide theoretical guidance for the application of materials in engineering.

(1) Prediction of equivalent mechanical properties of SMPNs

There are many methods for effectively predicting the thermomechanical properties of nanoparticlereinforced composites, including the micromechanical methods (e.g., the self-consistent theory [69-73], the Mori-Tanaka method [74], the differential methods [75], etc.) and the finite element methods. 
Jana et al. investigated the effects of the coefficient of linear thermal expansion (CLTE) of SMPUs and their nanocomposites (reinforced phases: organic clay, carbon nanofibers (CNF), SiC, and carbon black) [75]. The results showed that compared with the filler ( $\mathrm{SiC}$ ) with an aspect ratio of 1 , the nano-fillers with large aspect ratios (such as organic clay and CNF) had more obvious effects on the CLTE of the composites. The results also demonstrated that the Kerner model was better in CLTE prediction for spherical nanoparticle composites and the Halpin model was more suitable for organic clay and CNF inclusions.

SMPNs are temperature-sensitive materials. Many theoretical models for predicting the effective mechanical properties of composites at different temperatures have been proposed. Yang et al. established a micromechanical model considering the non-uniformity in the microstructure of CNTs/SMPs nanocomposites based on Liu's phase transition model and the Mori-Tanaka theory [76, 77]. They studied the effects of effective mechanical behavior at different temperatures and with different microstructural parameters. The results revealed that the degree of CNT aggregation had a significant effect on the effective properties of composites. The model of Yang et al. assumed that CNTs were uniformly distributed in the polymer, but did not consider the effect of the random orientation of CNTs on the effective mechanical properties of SMPNs.

Zare et al. used existing models for predicting composite yield strength and tensile strength, including the Kunori-Geil, the Piggott-Leidner, the Sato-Furukawa, the Pukanszky, and the Takayanagi models to evaluate the interface adhesion properties of SMPNs with different inclusions [78]. Velmurugan et al. predicted the effects of microstructural parameters and strain rates on the mechanical properties of multi-walled carbon nanotube (MWCNT)/SMP nanocomposites [79]. Mahmoodi et al. predicted the relationship between the equivalent elastic modulus and temperature of $\mathrm{SMP} / \mathrm{SiO}_{2} \mathrm{com}-$ posites based on the phase transformation theory [80]. Abishera et al. predicted the shape recovery properties of CNT/epoxy composites [81]. Jarali et al. extended Eshelby's problem of single inclusion to SMPNs with two different inclusions (fibers and CNTs). The effective modulus and inelastic strain tensor of the composites were deduced by obtaining the eigenstrain of the two different inclusions. The analytical solutions of Eshelby's problem for cylindrical inclusions with two different material properties in the inelastic body were obtained under the condition of small-strain deformation after a two-step homogenization procedure [82].

Taherzadeh et al. established a 3D finite element model of representative volume element of graphene nanoplatelet (GNP) shape-memory composites in ABAQUS and analyzed the effects of different volume fractions and inclusion aspect ratios on the thermomechanical properties of SMPNs [83]. Pan et al. established a finite element model with a spherical particle-reinforced SMPN through a representative volume element (RVE) created by a random sequential adsorption algorithm. Numerical simulations of the mechanical properties and SME behavior of the RVE showed that the elastic modulus and recovery stress increased significantly by adding $15 \%$ glass beads to SMPs. The shape fixing ratio slightly deteriorated due to the filler particles, but the effective shape recovery ratio hardly changed for dilute inclusion cases [84].

These reports generally assume that the inclusions are in ideal contact with the matrix. However, matrix and reinforcement will form an interfacial layer through complex physical and chemical reactions during the curing process, which has a vital impact on the thermomechanical properties of composites. In addition, interfacial damage is one of the basic damage modes of composite materials. Interfacial damage not only weakens the effective properties of composites, but also induces macro-fracture of materials and affects the life of structures. Therefore, it is necessary to investigate the effect of interfacial damage on SMPCs, which undergo large deformation at high temperature.

\section{(2) Buckling behavior of SMPCs}

Various forms of failure for traditional fiber-reinforced composites subjected to compressive load include shear failure, tensile failure, fiber dislocation, and fiber brittle fracture [85]. Traditional resin composites have higher stiffnesses and smaller buckling deformation ranges, while fiber-reinforced SMPCs show hyperelastic behavior at high temperature $\left(T>T_{\mathrm{g}}\right)$ and their fiber buckling deformation ranges enlarge [86]. During the shape memory cycle, SMPCs inevitably undergo bending deformation with large curvature at high temperatures. In this state, the compression zone of SMPC undergoes microscopic buckling, which affects the macroscopic stiffness of the structure (as shown in Fig. 4). 
Therefore, it is necessary to study the mechanical behavior of fiber-reinforced flexible-matrix composites and to investigate the relationship between macro-bending of SMPC and fiber buckling [87].

Various theoretical frameworks used to investigate the mechanical behavior of fiber-reinforced flexible-matrix composites include the homogenization theory, the Bloch wave theory, and the strain energy function method.

The homogenization theory is used to analyze the constitutive behavior of flexible-matrix composites with periodic structure. By assuming that the fiber and matrix are both isotropic and incompressible hyperelastic materials, Lopez-Pamies et al. used the second-order homogenization theory and the neoHookean model to construct a three-dimensional constitutive model of flexible-matrix/fiber-reinforced composites under finite strain conditions [88, 89]. Jiménez et al. subsequently improved their model, but could not explain the microscopic constitutive behavior of the material[90, 91].

The Bloch wave theory has the ability to adequately explain and predict the microstructural damage of composite materials. Triantafyllidis et al. used this theory to obtain the two-dimensional theoretical solution of critical curvature and characteristic buckling wavelength of flexible-matrix composites under bending load and verified the theoretical results using the three-dimensional finite element method [92].

The deformation behavior of material can be solved using the total strain energy function, which is the sum of the tensile, compressive, and shear strain energies of each phase and the shear strain energy between phases.

Francis et al. used the neutral plane as a boundary to divide the cross section of the composite into a tension zone and a compression buckling zone [93]. The strain energy of SMPC, the fiber buckling strain energy, and the shear strain energy were established. Microscopic characteristic parameters such as the half-wavelength and the amplitude of SMPC buckling were obtained using the principle of minimum energy. Wang et al. proposed a micro-buckling model for unidirectional fiber-reinforced shape-memory composites capable of predicting the buckling wavelength, which, however, did not consider the influence of ply angle on micro-buckling and post-buckling behavior [94].

The above models are all based on the assumption that fibers in the compression zone are already buckled. As a result, these models are unable to adequately explain the states before buckling and critical buckling. Leng et al. assumed that the cross section of the bent SMPC plate consisted of a tension zone, a compressed non-buckling zone, and a compression buckling zone, and thereby introducing a critical buckling concept [87]. Zhang et al. further perfected the theory by considering the boundary effect of fiber-reinforced buckling composite laminates on the basis of Leng's research [95].

This section summarizes the prediction models for thermomechanical behavior of SMPs/SMPCs. It can be seen that the research on the constitutive behavior of SMPs is more in-depth, providing theoretical bases for their applications in aerospace, $4 \mathrm{D}$ printing, and other fields. However, there are few studies on the mechanical behavior of SMPNs and SMPCs. The large deformation mechanism of SMPCs, in particular, seems to be neglected. The assumptions of the existing prediction models are ideal, and it is necessary to investigate the interface of SMPC. The cross-scale correlation between fiber micro-buckling and macro-structure deformation should be further investigated to provide sufficient theoretical bases for SMPC design and to broaden its range of applications.

\section{Applications of SMPs/SMPCs}

A comprehensive understanding of the properties of SMPs/SMPCs will help us use them more effectively and rationally. Shape-memory polymers and their composites have many advantages, such as recoverable strain storage capacity, excellent deformability, and variable stiffness, which facilitate their wide applications in many fields. However, the materials also have their limitations. For one-way SMPs, the greatest feature is that they can only complete SME once. Without external reprogramming, they cannot be used for multiple times. On the other hand, the service life and recovery accuracy of the composites are affected by many factors such as the programmed shape, the number of shape memory cycles, etc. In particular, damage to fiber-reinforced composites will occur after many SME cycles. This is limited to materials mostly used in structures requiring only one SME to achieve deployment, such as space-deployable structures, vascular stents, etc. The SME of material is used to transport the structure with temporary shape and deploy it to the desired shape at a specified position and time, which solves the problem of packaging and transportation of large structures. On the other hand, the viscoelastic and temperature-sensitive properties of materials must be considered 

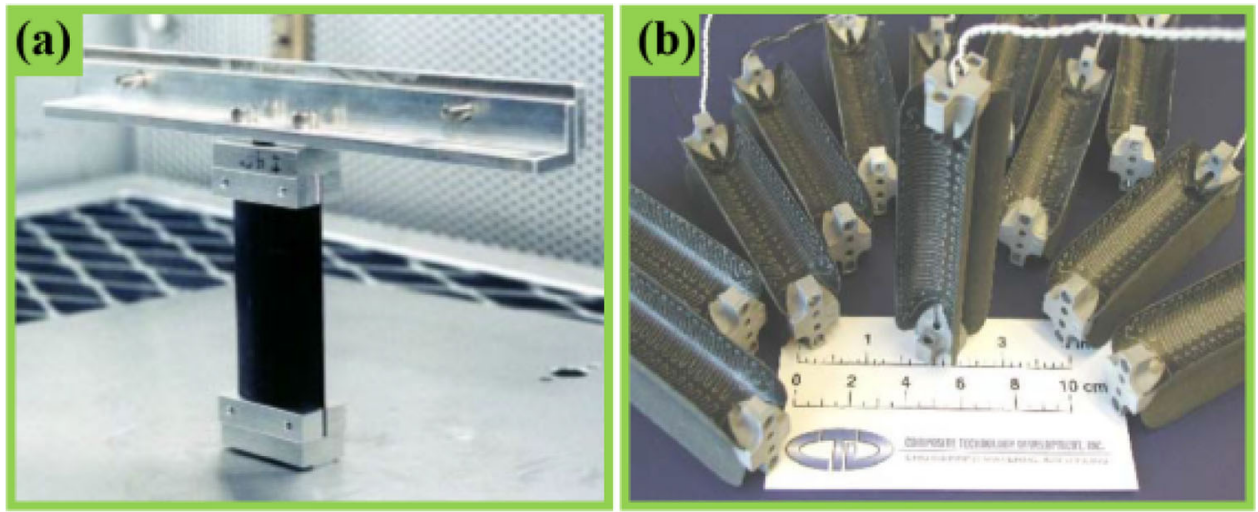

Fig. 5. The hinge developed by CTD: a originally designed hinge [97]; b optimized hinge [98]

in their applications. The creep behavior of SMPs/SMPCs will cause partial shape recovery during storage and transportation, especially when the external temperature fluctuates greatly, which means relatively high environmental regulation requirements for structures in storage and transportation [2]. Although the material has some shortcomings, its unique properties still have important application value. This section reviews the applications of SMPs in aerospace and four-dimensional (4D) printing.

\subsection{Applications in Aerospace}

Nowadays, for space-deployable structures, the deployment of the solar wing must be accomplished through the initiation of explosive devices. However, due to the transient effects caused by these explosive devices, the satellites require demanding mechanical tests. NASA reported that for 88 flight failures, the detonation of explosive devices accounted for more than $71 \%$ of the cause of failure. This statistic reveals the severity of this threat to the completion of space missions. Therefore, NASA has established a comprehensive set of management practices [96].

The SMPC has high stiffness below $T_{\mathrm{g}}$ and maintains this property after being slowly deployed above $T_{\mathrm{g}}$, which typically takes a few minutes to complete. Compared with the time required for the explosive device (milliseconds) to detonate, it can effectively avoid harsh impact, reduce flight risk, and considerably improve the reliability of the aircraft. The $S M P C$-based space-deployable structures have gained more and more attention and been successfully applied to expandable hinges, trusses, beams, antennae, and space capture devices. In addition, the micro-buckling of SMPC enables it to obtain greater deformation capacity, which increases the deployment/contraction ratio.

\section{(1) SMPC hinge}

Generally, the hinge is used to provide a driving force for the space-deployable structure. However, the conventional mechanical hinge uses spring to generate the driving force, which causes vibration during deployment. The SMPC deployment process is slow and can effectively avoid such vibration problems. The Composite Technology Development, Inc. (CTD) developed a thermally actuated hinge using two straight SMPC plates (as shown in Fig. 5a) and optimized the cross section of the SMPC to an arc for greater driving torque (Fig. 5b) [25, 97, 98].

Figure $6 \mathrm{a}$ is a hinge designed by Lan et al., which consists of two SMPC sheets with a curvature of $120^{\circ}$, and is actuated by a thin-film heater attached to the surface of the composite [99, 100]. Experiments have shown that when the driving voltage is $20 \mathrm{~V}$, the temperature of the hinge surface is about $80^{\circ} \mathrm{C}$, and the full deployment time of the hinge is $100 \mathrm{~s}$ (as shown in Fig. 6b). In addition, Lan et al. performed a ground deployment verification experiment of a hinge-driven solar array panel on a sliding platform with a full deployment time of $80 \mathrm{~s}$ (as shown in Fig. 6c).

(2) Deployable structures of SMPCs

The Composite Technology Development, Inc. also designed a variety of deployable structures using SMPCs to meet the needs of microsatellites, including the deployable beam (as shown in Fig. 7a). In the 

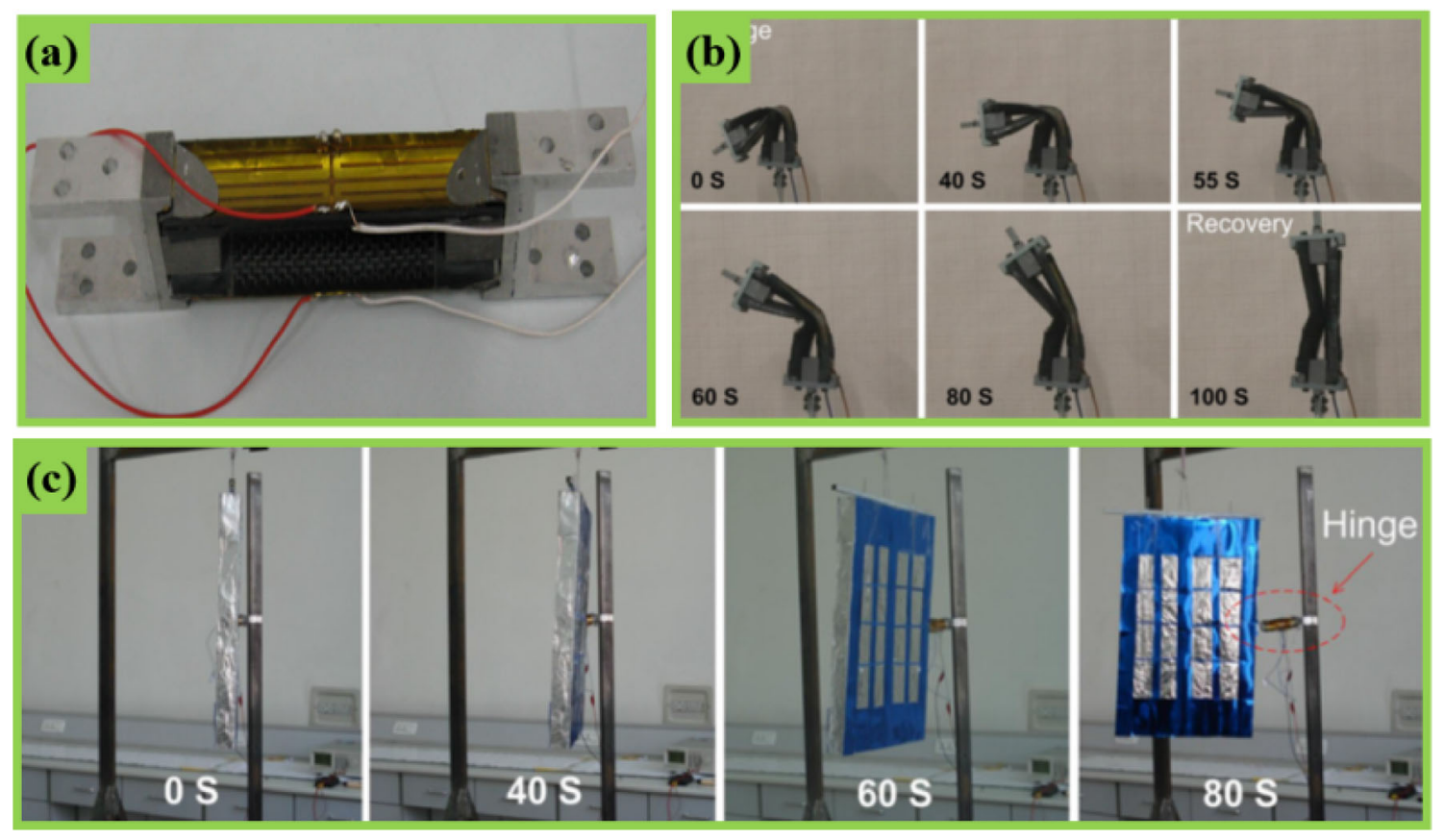

Fig. 6. SMPC hinge designed by: a hinge; $\mathbf{b}$ hinge unfolding process; $\mathbf{c}$ ground-validation experiment of hinge-driven solar array panel[99, 100]
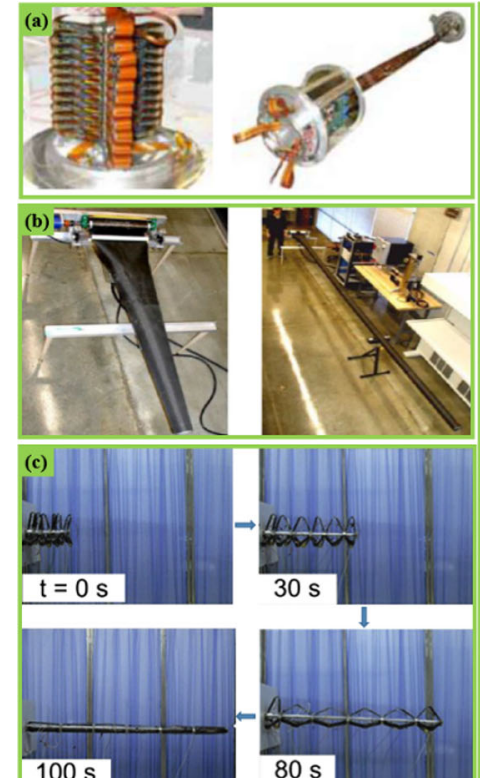

$100 \mathrm{~s}$
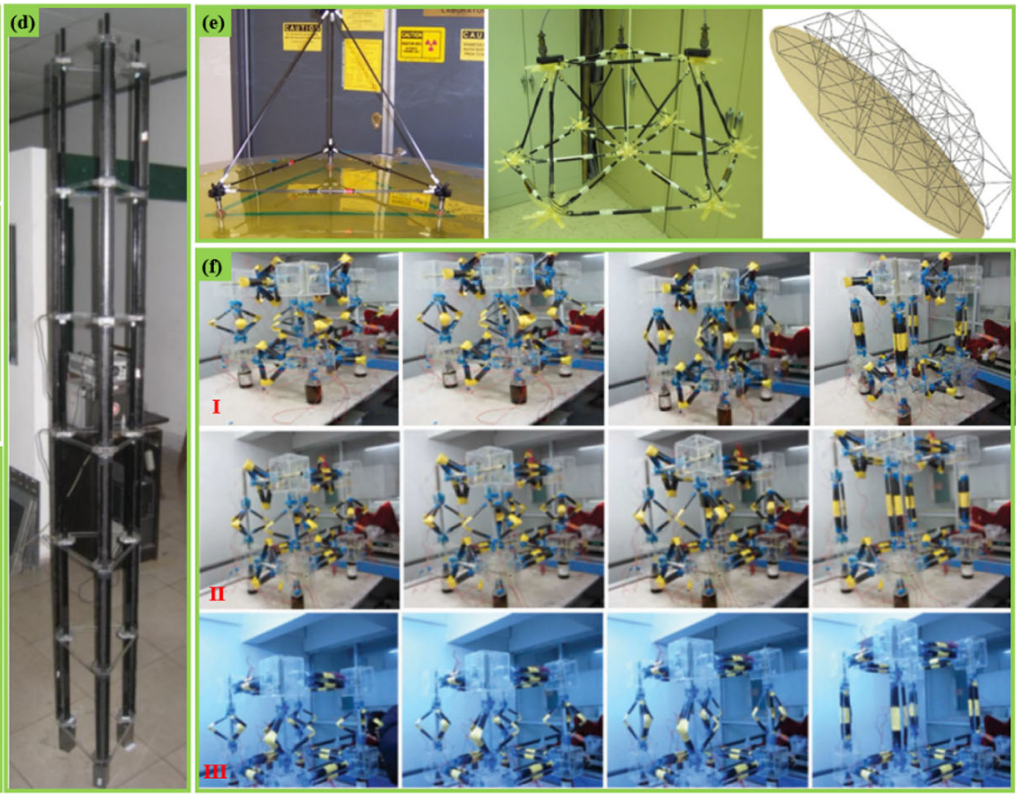

Fig. 7. SMPC space-deployable beam structure: a deployable beam [101]; b crimped beam structure [101]; c unfolding process of deployable beams developed by [102]; $\mathbf{d}$ three longitudinal beam trusses [26]; e tetrahedral truss [103]; $\mathbf{f}$ three longitudinal beam trusses: I. the first direction; II. the second direction; III. the third direction [104]

contracted state, the composite beam is in a zigzag shape, and the SMPC is heated after reaching the specified orbit to achieve deployment. DSX/PowerSail developed the SMPC-crimped beam structure, which can be crimped and unfolded to achieve the contracted emission and on-orbit deployment of flexible solar cells connected to it (as shown in Fig. 7b) [101]. In addition, Zhang et al. developed a deployable beam consisting of SMPC sheets with a circular cross section that can be shrunk into an 

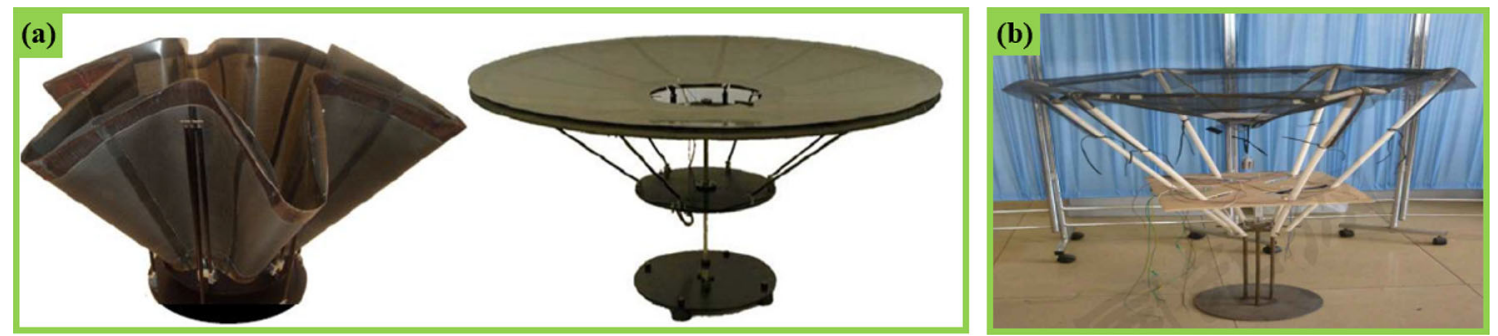

Fig. 8. Deployable antenna: a deployable antenna developed by [105]; b deployable antenna developed by [106]
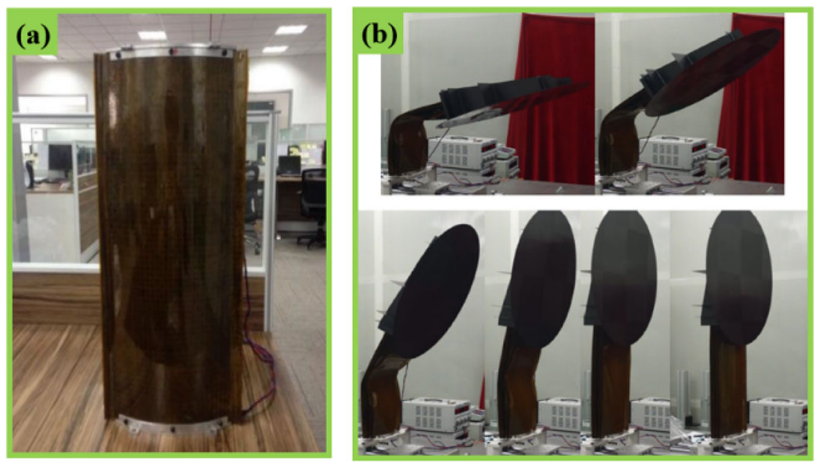

Fig. 9. Deployable spaceborne mechanism developed by [107]: a SMPC hinge; b ground deployment experiment verification of SDM

"M" shape. The deployment of the beam can be completed within $100 \mathrm{~s}$ (as shown in Fig. 7c) [102]. $\mathrm{Li}$ et al. investigated the dynamic mechanical properties (such as mode shapes) of three longitudinal beam trusses through experiments and finite element simulations (Fig. 7d) [26]. Shook et al. developed a tetrahedral truss consisting of springs and SMPCs to reduce structural vibration and increase structural stiffness (Fig. 7e) [103]. Leng et al. developed a cubic deployable truss structure with three-span beams and the cubic frame, which can be used in future aerospace applications [104]. The first- or multidirectional deployment can be achieved by controlling the energization sequence of heaters (Fig. $7 \mathrm{f}$ ).

Keller et al. used SMPCs to develop a deployable high-precision antenna (Fig. 8a), the good deployment accuracy of which facilitated NASA's Mars exploration mission [105]. The Harbin Institute of Technology (HIT) also conducted a related study on shape-memory deployable antennas (Fig. 8b) [106].

In recent years, Chen [107], CTD [108], and Liu [109] have developed new space-deployable structures based on SMPCs.

Chen et al. developed a space-deployable mechanism (SDM) using SMPCs and composite spring strips for space-deployable antennas, which drove the antenna reflector through a hinge of symmetrical distribution of eight-layer SMPC sheets, as shown in Fig. 9 [107]. The optimization of the design meant that the cross section of the single-layer SMPC sheet was conceived as a multi-arc section to improve the overall mechanical properties of the structure. The designed space structure integrated functions with structures. In addition, the SMPC shell acted as a damper to prevent damage to the structure caused by the strong impact from the reflector during deployment; and the composite spring belt greatly enhanced the recovery torque of the SDM, which ensured the high development accuracy of the structure.

In order to meet the high power and large area requirements of the solar array for small spacecraft, such as the micro-/nano-satellites for the future, as shown in Fig. 10, Alexi Rakow et al. of CTD designed a composite lightweight array utilizing the shape-memory polymer (CLASP) based on elastic memory composite (EMC) linear hinges [108]. The EMC hinges in the CLASP structure were folded in to a "Z" shape to achieve the smooth, slow, and controllable deployment of the solar array. 

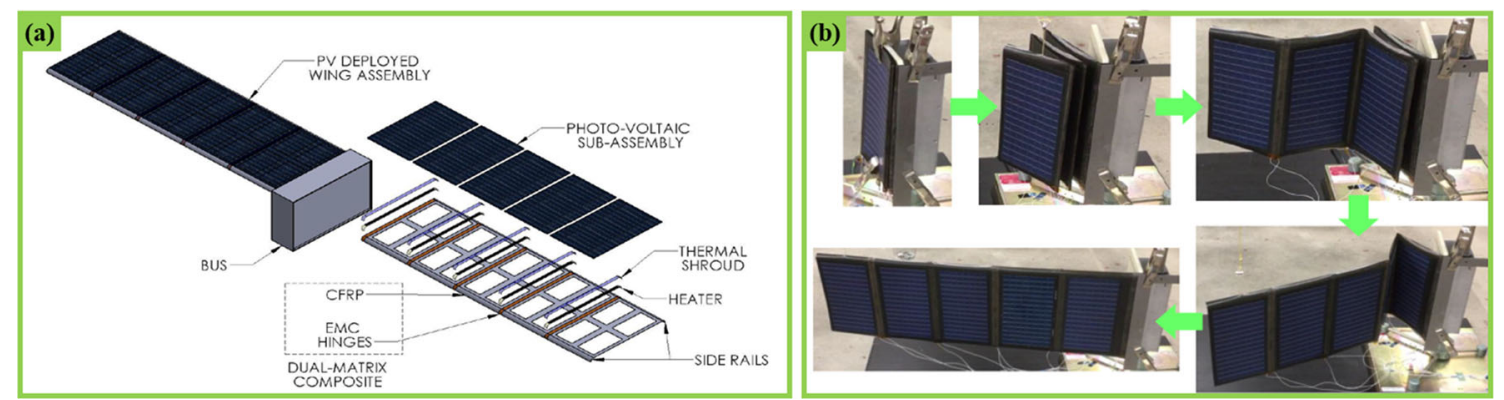

Fig. 10. CLASP developed by CTD: a schematic diagram of solar panels; b CLASP ground experimental verification of $6 \mathrm{U}$ cubic star $[108]$
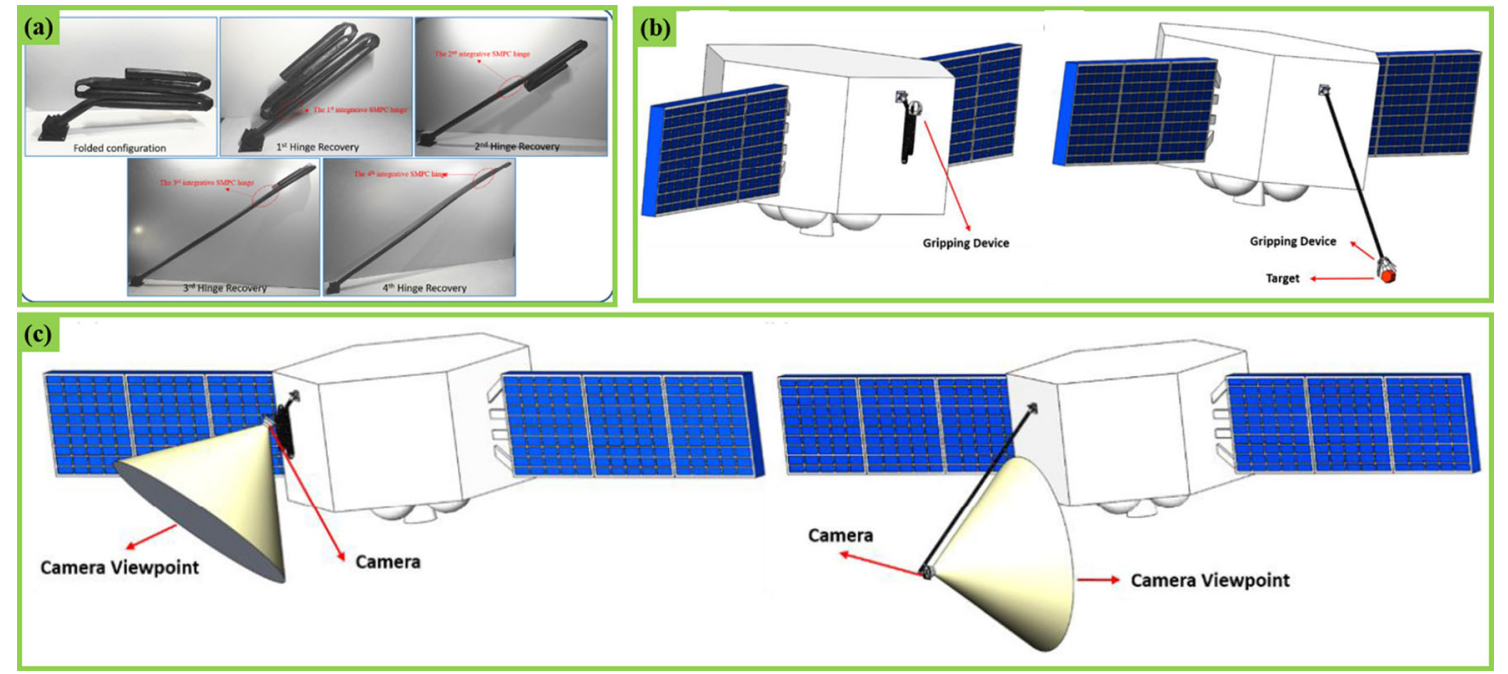

Fig. 11. Self-deployment structure and application prospects: a shape memory recovery process; $\mathbf{b}$ self-driven gripping; c multi-angle imaging system [109]
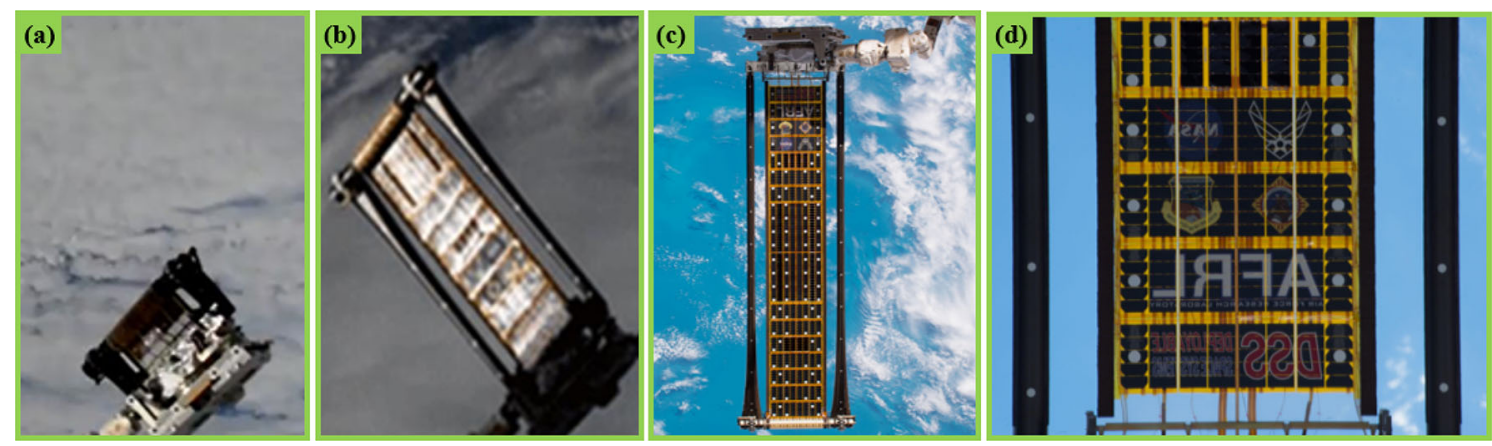

Fig. 12. The in-orbit deployment test verification of ROSA developed by NASA: a contraction state; b deploying; c deployment completed; d partial enlargement after deployment [110]

Recently, Liu et al. fabricated a self-driven multi-level integrated hinge structure using SMPCs (as shown in Fig. 11), which holds promising potential applications in self-driven gripping devices and multi-angle imaging systems [109].

With the latest developments in the aerospace industry, the traditional solar wings can no longer meet the power demand of hundreds of kilowatts in the spacecraft for the future. Therefore, the development of flexible large-area solar wing needs to be addressed. The Roll Out Solar Array 
(ROSA) developed by NASA and AFRL using the C-beam composite thin-walled structure successfully completed the on-orbit deployment verification in 2017 (as shown in Fig. 12) [110]. ROSA used a conventional rigid thin-wall composite with the maximum strain rate of approximately $1.5-2 \%$ and the maximum structural thickness of approximately $0.2 \mathrm{~mm}$ to meet the design requirements with general deployment/contraction ratios. The maximum strain rate of SMPCs can reach approximately 8-10\% [3, 91, 100], and the maximum thickness of the corresponding structure can reach $1 \mathrm{~mm}$, which will greatly improve the stiffness and fundamental frequency of the space-deployable structure in the unfolded state of the rail. In addition, under the premise that the minimum fundamental frequency of the unfolded state is constant, the ultimate deployment area of the SMPC-based deployable structure will be much larger than that of the conventional rigid thin-walled composite expandable structure, which is expected to be applied to large flexible solar wings. Therefore, SMPCs play a subversive and leading role in promoting the innovation and development of aerospace technology.

\subsection{D Printing}

The manufacturing technology of three-dimensional (3D) printing additives provides designers with the possibility of designing and manufacturing complex structures. The four-dimensional (4D) printing adds a time dimension to the 3D printing; that is, the shape/function/properties of the structure can change with time under external stimuli. This concept was first proposed by Tibbits in 2013 $[111,112]$. The printed structures are activated by the external environment to achieve self-assembly, self-adaptation, multi-function, and structural re-configurability. Compared with the traditional fabrication method of SMPs/SMPCs, 4D printing has the ability to manufacture seamless joints, achieve cross-scale integration into complex structures, and create individualized products. Furthermore, largescale equipment is not needed in the preparation process, which shortens the product design and manufacturing time and saves raw materials.

4D printing makes it possible to print simple structures that can self-assemble into complex structures under external stimuli. For example, it would be possible to enable the self-assembly of larger complex antennae or satellites from small simple structures printed in space. 4D printing integrates sensing and driving into materials, eliminating the need for external motor drives, and reducing the number of structural parts as well as assembly time.

In addition, 4D printing has great application value in adaptive and multi-functional personalized medical devices, such as tracheal stents, vascular stents, and other similar devices. The printed devices are compressed into smaller sizes in vitro, and implanted into lesions with minimally invasive surgery, which can then self-assemble in the body under external magnetic fields [113].

\subsubsection{Deformation Types}

The 4D printing of SMPs can achieve multi-dimensional deformation, including deformation from 1D-to-1D/2D, 2D-to-2D/3D, and 3D-to-3D.

(1) Deformation from 1D-to-1D/2D

The 1D structure can be linearly deformed into another 1D structure through shrinkage/expansion, or into a 2D structure through bending/folding. Yu et al. printed a deformable truss capable of achieving the 1D linear deformation through compression and expansion (Fig. 13a) [114]. Yu, Qi, and Liao et al. presented the 1D rods that were bent into arcs with different curvatures (Fig. 13b) [114-116]. Huang printed a shape-memory polyurethane sheet and placed it in water at $85^{\circ} \mathrm{C}$ to achieve folding deformation (Fig. 13c) [117]. Qi et al. successfully created a printed active composite (PAC) hinge based on SMPs and elastomerics using the PolyJet technology (Fig. 13d) [118]. The curling and folding deformation of the hinge was achieved by applying in-plane pre-deformation. Mao et al. also developed a controllable folding structure (Fig. 13e) [119].

(2) Deformation from 2D-to-2D/3D

Wagner et al. designed three types of $4 \mathrm{D}$ printed deformable active meta-materials. The thermomechanical and shape recovery properties of the printed samples were characterized [120]. They also showed that the "ETH" logo assembled by the auxetic reentrant honeycomb unit cells recovered from the $2 \mathrm{D}$ compressed shape to the 2D original shape (Fig. 14a). Gladman et al. printed some 2D planar 

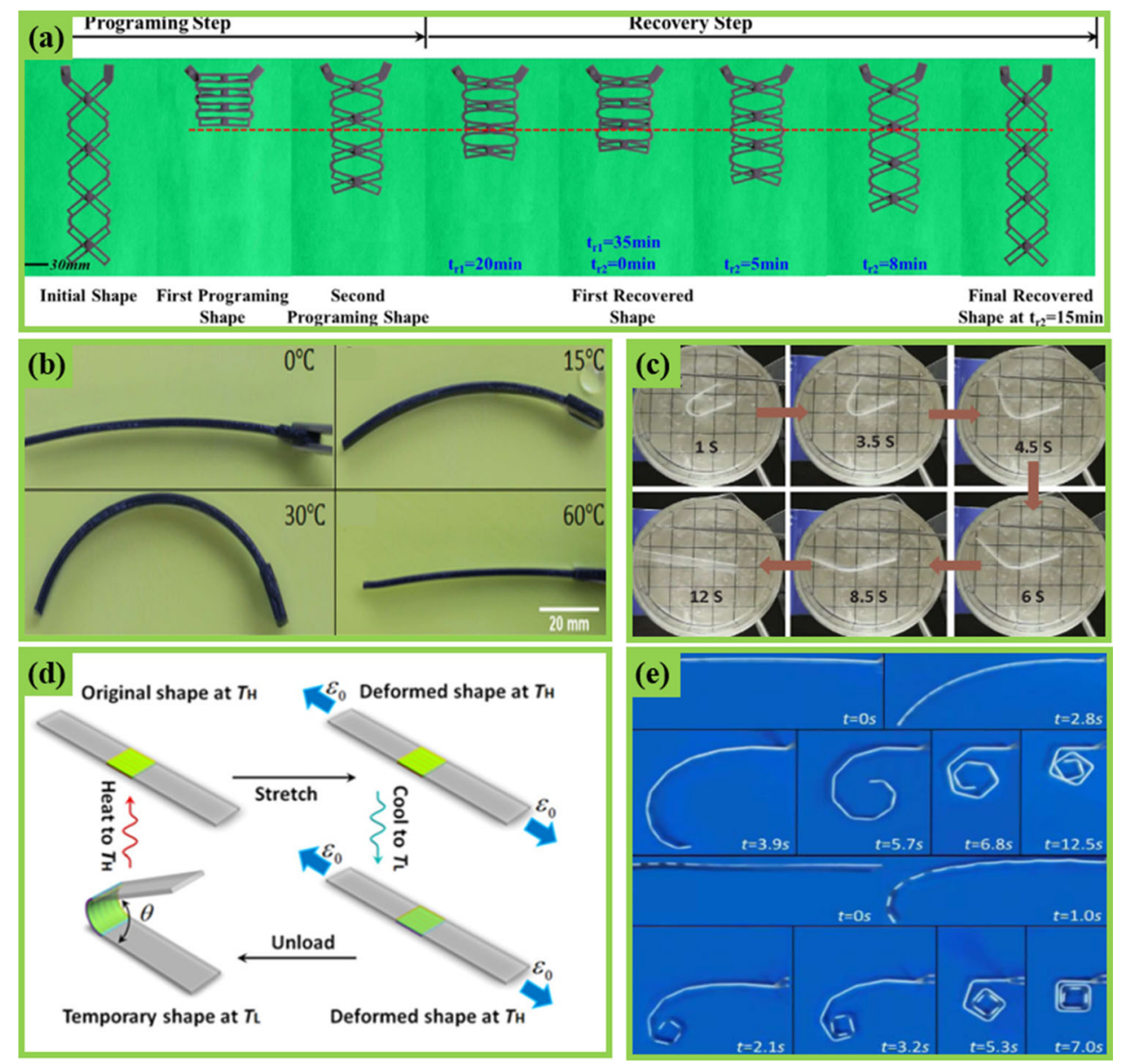

Fig. 13. 1D-to-1D and 2D deformation of the printed structure: a contraction/expansion [114]; b 1D structure bending deformation to 2D structure [115]; c 1D structure folding deformation to 2D structure [117]; $\mathbf{d}$ foldable hinges developed by [118]; e controllable folding structure developed by [119]

structures, capable of assembling into complex flower shapes by twisting and bending under external stimuli (Fig. 14b) [121]. Furthermore, Qi et al. printed a composite structure capable of deforming into different shapes at different temperatures, which consists of SMPs with different $T_{\mathrm{g}}$. After the composite structure is programmed once, as the temperature increases, the SMP is gradually activated to achieve controllable and orderly deformation of the structure. The composite structure was used to design smart trestles, smart insect-like structures, and smart hooks which can be deformed from a $2 \mathrm{D}$ structure to a 3D structure by self-bending [115]. Qi et al. also developed a theoretical model for predicting the structural deformation behavior [118]. Combining 4D printing with origami art, they used the hinge featured in Fig. 13d to fabricate foldable boxes, airplanes, and pyramids (Fig. 14f). Liao et al. applied pre-strain to the printed structure by adjusting the printing parameters, such as printing speed and nozzle temperature [122]. Printed 2D plates via the fused deposition modeling (FDM) technology can automatically curl or twist under heating without programming (Fig. 14g). The self-assembled mailboxes designed by Miao et al., self-assembled flowers exhibited by Zhang et al., and self-assembled balls demonstrated by Ying were all deformed from 2D temporary shapes to 3D structures $[117,123,124]$.

(3) Deformation from 3D-to-3D

Magdassi first integrated the stereolithography (SLA) 3D printing technology with SMPs into the 4D printing technology. The printed cardiovascular stent, the Eiffel Tower, and bird are deformable 

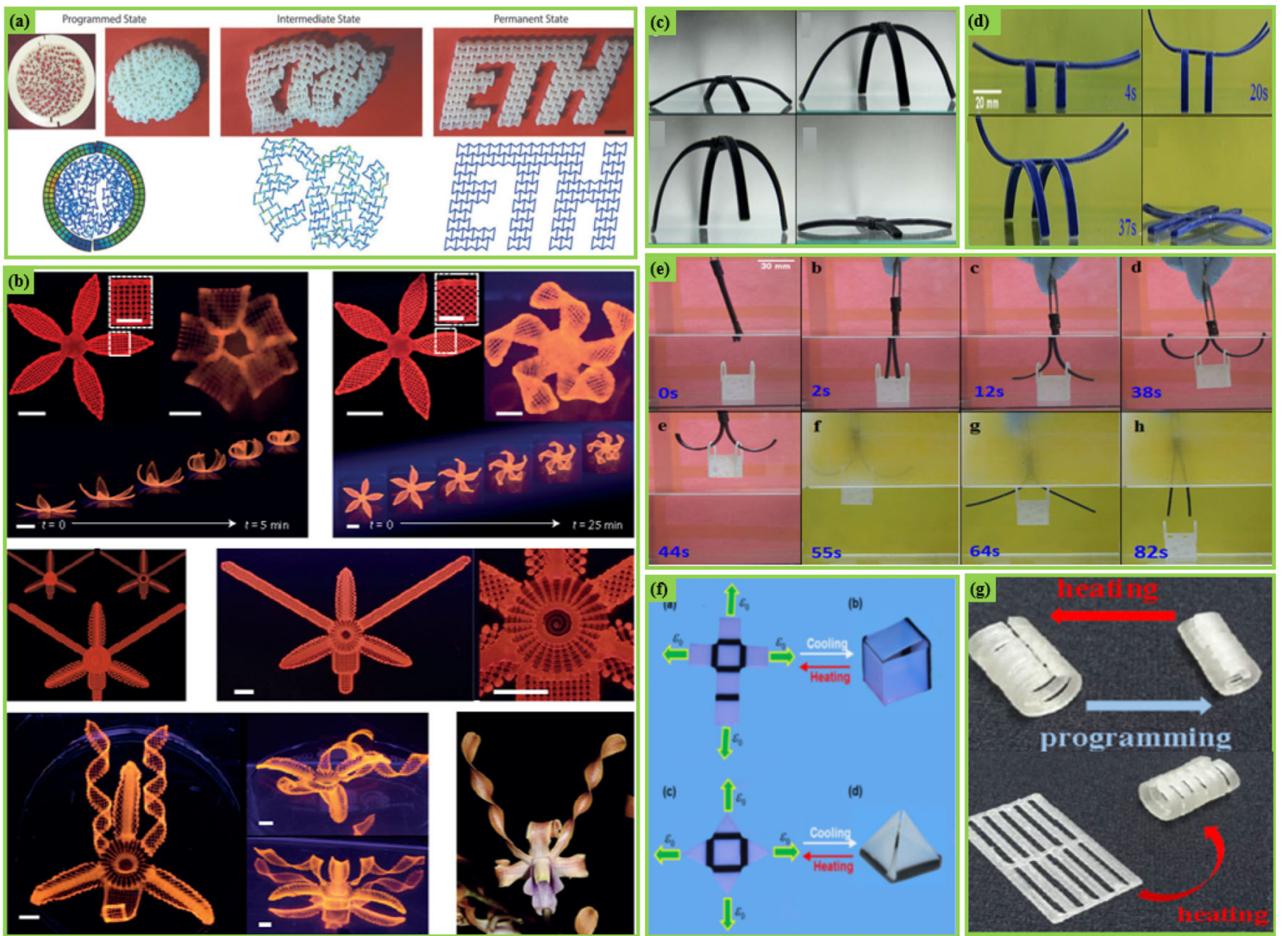

Fig. 14. 2D printed structure from 2D to 3D deformation: a 2D deformable honeycomb structure [120]; b 2D planar structure twists, bends, and deforms, then assembles into flowers [121]; c smart trestle [112]; $\mathbf{d}$ smart insect-like structure [112]; e smart hook [112]; f foldable cartons and pyramids [118]; g automatic curling hinges [122]
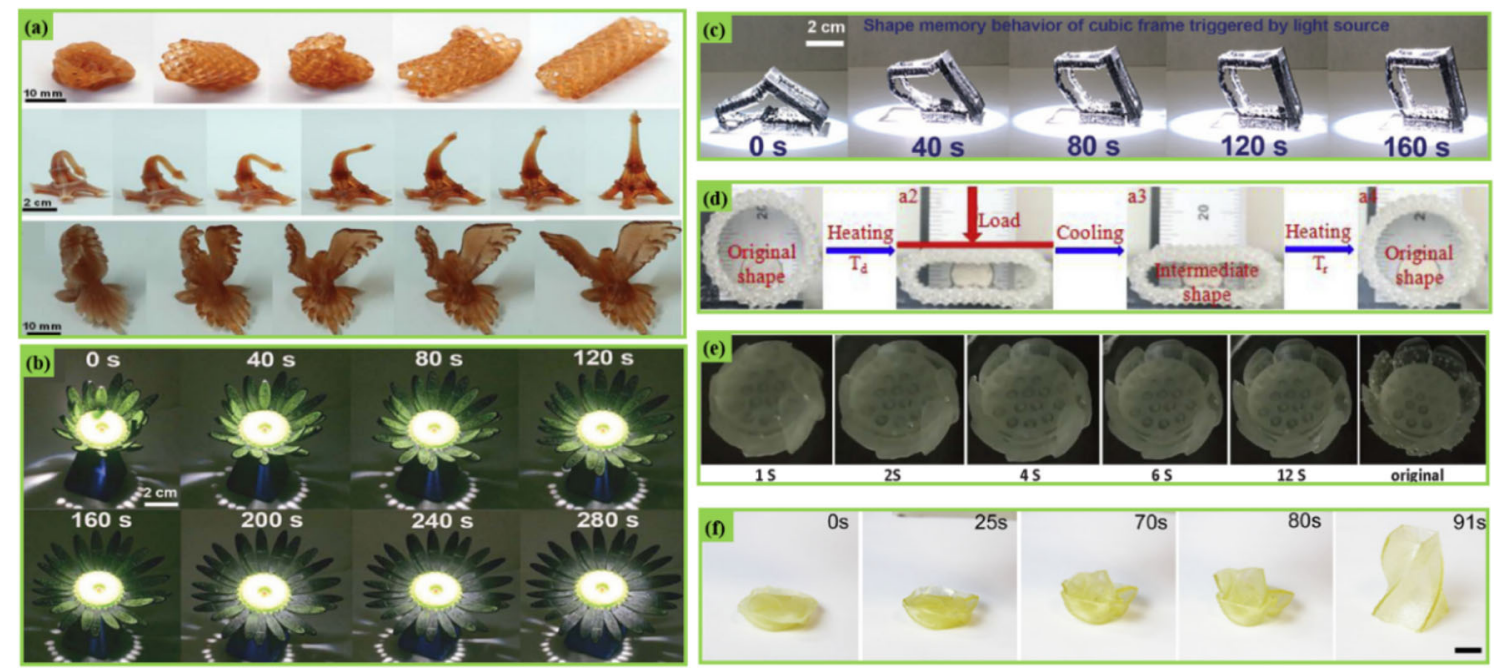

Fig. 15. Deformation from 3D to 3D: a printed cardiovascular stent, Eiffel Tower, and bird models by [125]; b light-driven bionic flower and $\mathbf{c}$ printed cube [126]; $\mathbf{d}$ printed circular braided tube [127]; e deformable lotus root [117]; f deformable vase [128] 

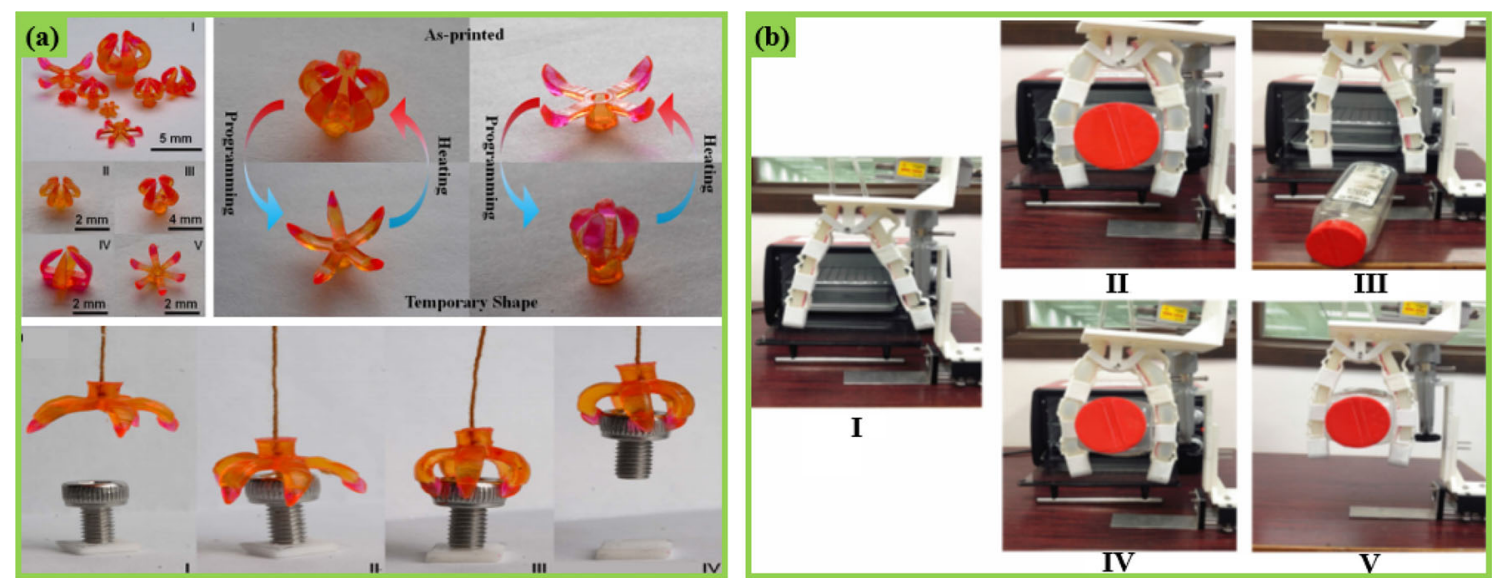

Fig. 16. 4D printed capture structure: a printed grab structure gripping screw [130]; b Chen's grab experiment: I. the variable-stiffness robotic fingers; II. grab the bottle through pneumatics $\left(T>T_{\mathrm{g}}\right)$; III. the bottle drops when the air is off; IV. grab the bottle by pneumatics $\left(T>T_{\mathrm{g}}\right)$; V. the bionic fingers remain in the grip state when pneumatically closed $\left(T<T_{\mathrm{g}}\right)[131]$

with temperature (Fig. 15a) [125]. Chen et al. fabricated cubes, bionic flowers, and other structures that could be actively deformed under sunlight (Fig. 15b, c), providing vast opportunities for the design and manufacture of bionic smart devices and soft robots [126]. Zhang et al. printed circular braided pipes (Fig. 15d) and investigated the influence of geometric parameters on the SMB of pipes. They also proposed their potential applications in functional composites [127]. Deformable lotus roots and vases were also printed by Zhao [117] and Kuang [128], respectively (Fig. 15e, f).

\subsubsection{Applications of $4 D$ Printing}

$4 \mathrm{D}$ printing is suitable for rapid prototyping of complex structures and can integrate information and functions into structures, adequately fulfilling the automation requirements in the field of robotics. As a result, 4D printing carries broad application potential in robotics.

The catching structure of bionic robots has been extensively studied. The gripping performance of the structure has been verified by experiments involving gripping cap [129], screw [130] (Fig. 16a), and mineral water bottle [131]. Chen developed a variable-rigidity robotic finger by combining the 4D printing technology with an aerodynamic structure. This bionic finger has the ability to hold a bottle by heating (Fig. 16) [131].

SMPs are biocompatible, degradable, and remotely driven, making it an ideal tissue engineering biomaterial. Ge et al. printed a series of thermally driven vascular stents with different geometric parameters (height, diameter, number of joints, ligament diameter, and angle between ligaments) for dilating arterial stenosis using the SLA printing technology [130]. Leng et al. prepared the magnetically driven vascular stents through direct writing technology (Fig. 17a) [28]. In vitro deployment testing demonstrated that the vascular stent could be deployed in $10 \mathrm{~s}$. Cohn et al. prepared a customized shape-memory tracheal stent using SLA, and the in vitro deployment experiments showed that the stent could be deployed within $14 \mathrm{~s}$ (as shown in Fig. 17b) [132]. Zhang et al. prepared the biomimetic porous tissue scaffolds, the surface morphology, thermodynamic mechanical properties, biocompatibility, and shape memory effects of which were characterized [133]. The results revealed that the printed scaffolds were highly biocompatible (Fig. 17c), making them conducive to the development of novel functional biomedical stents.

Although the 4D printing technology has shown great application potential and research value, it is still in its infancy. The surface structures fabricated by $4 \mathrm{D}$ printing are relatively rough, especially by the FDM printing technology. With the increasing complexity and refinement of printing structures, it is particularly important to optimize the manufacturing process and establish a cross-scale association of the surface microstructure and internal defect evolution of the printed material with the macroscopic thermomechanical properties and life of the fabricated structure. 

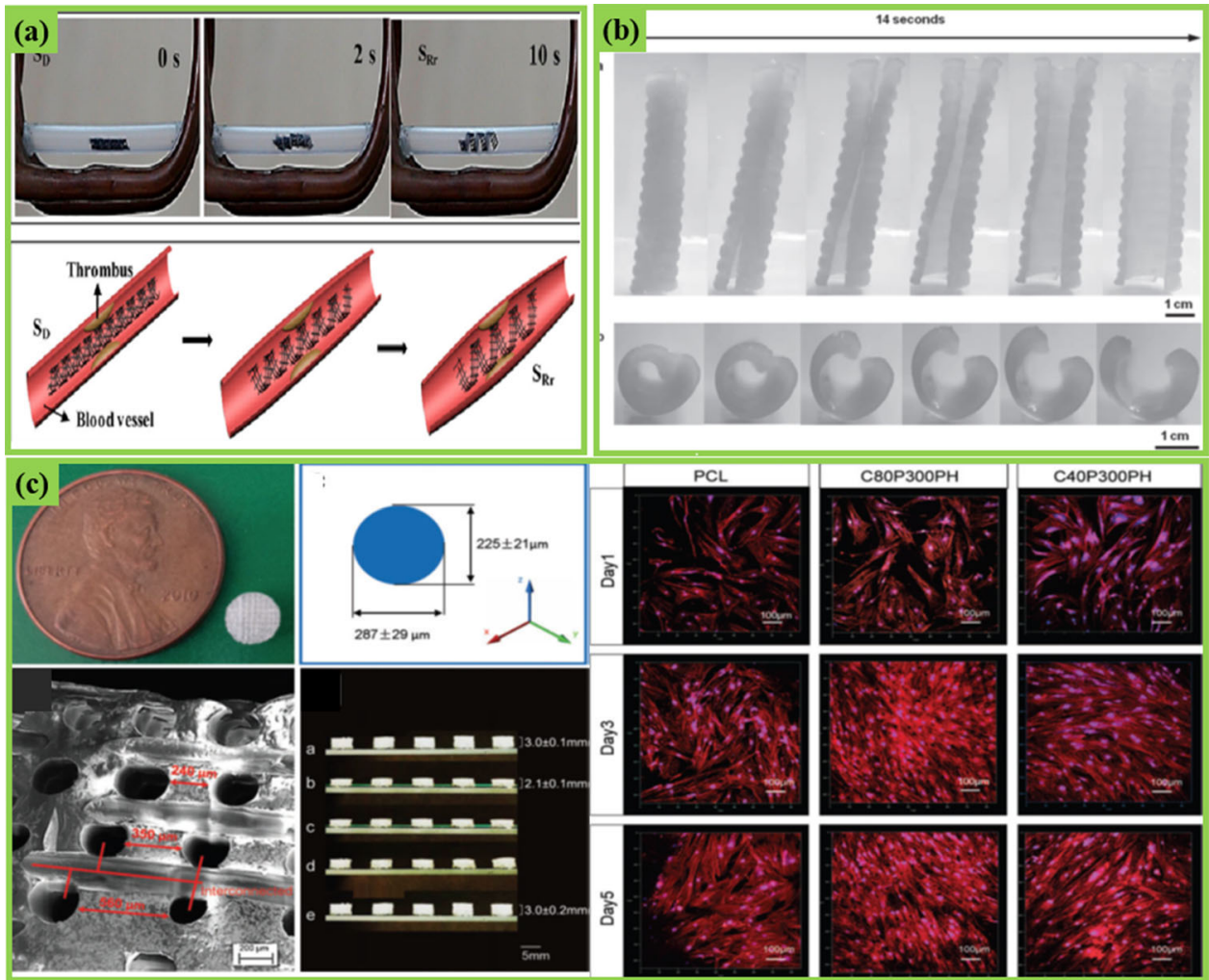

Fig. 17. 4D printed medical devices: a deployment process of the vascular stent under magnetic field [28]; b tracheal stent recovery process [132]; c the scaffold prepared by Zhang et al.: the printed specimen compared to a one-cent coin; pore diameters, SEM image, shape recovery process, and microscopic images of MSC growth [133]

In the future, the thermoset SMPs and fiber-reinforced SMPCs need to be developed to meet the requirements of the aerospace industry. In addition, the thermal mechanical mechanisms involved in the printing process need to be specified to improve the design of printed structures as well as the print quality.

\section{Conclusions}

SMPs and SMPCs have the advantages of lightweight, large deformation, variable stiffness, and biocompatibility and have been widely used in the aerospace field and 4D printing of intelligent robots as well as for medical equipment. In conclusion, the mechanical models of SMPs, SMPNs, and SMPCs and their applications in space-deployable structures and 4D printing techniques have been reviewed. The possible research directions concerning SMPs and SMPCs in the future include:

(a) investigating the effect of interfacial damage on the effective properties of SMPCs under high temperature and large deformation (because the interface layer and its damage influence the life of SMPCs and induce macro-fractures);

(b) optimizing the process of printing manufacturing technology to make the surface of the printed structure smoother, especially for the FDM printing manufacturing technology;

(c) establishing a cross-scale association of the surface microstructure and internal defect evolution of the printed material with the macroscopic thermomechanical properties and life of the fabricated structure;

(d) research on the 4D printing technology of fiber-reinforced thermosetting shape-memory materials for aerospace applications.

The mechanical properties of SMPs/SMPCs and the deployable structures based on these materials have attracted more and more attention. It is expected that SMPs will be applied in more fields. 
Acknowledgements. This work is supported by the National Natural Science Foundation of China (Grant Nos. 11772109, 11632005 and 11672086) and the Foundation for Innovative Research Groups of the National Natural Science Foundation of China (Grant No. 11421091).

Open Access This article is distributed under the terms of the Creative Commons Attribution 4.0 International License (http://creativecommons.org/licenses/by/4.0/), which permits unrestricted use, distribution, and reproduction in any medium, provided you give appropriate credit to the original author(s) and the source, provide a link to the Creative Commons license, and indicate if changes were made.

\section{References}

[1] Liu Y, Du H, Liu L, Leng J. Shape memory polymers and their composites in aerospace applications: a review. Smart Mater Struct. 2014. https://doi.org/10.1088/0964-1726/23/2/023001.

[2] Mu T, Liu L, Lan X, Liu Y, Leng J. Shape memory polymers for composites. Compos Sci Technol. 2018;160:169-98. https://doi.org/10.1016/j.compscitech.2018.03.018.

[3] Leng J, Lan X, Liu Y, Du S. Shape-memory polymers and their composites: stimulus methods and applications. Prog Mater Sci. 2011;56(7):1077-135. https://doi.org/10.1016/j.pmatsci.2011.03.001.

[4] Zhao Q, Qi HJ, Xie T. Recent progress in shape memory polymer: new behavior, enabling materials, and mechanistic understanding. Prog Polym Sci. 2015;49-50:79-120. https://doi.org/10.1016/j.progpolymsci. 2015.04.001.

[5] Hu J, Zhu Y, Huang H, Lu J. Recent advances in shape-memory polymers: structure, mechanism, functionality, modeling and applications. Prog Polym Sci. 2012;37(12):1720-63. https://doi.org/10.1016/j. progpolymsci.2012.06.001.

[6] Hager MD, Bode S, Weber C, Schubert US. Shape memory polymers: past, present and future developments. Prog Polym Sci. 2015;49-50:3-33. https://doi.org/10.1016/j.progpolymsci.2015.04.002.

[7] Zhao W, Liu LW, Zhang FH, Leng JS, Liu YJ. Shape memory polymers and their composites in biomedical applications. Mater Sci Eng C Mater. 2019;97:864-83. https://doi.org/10.1016/j.msec.2018.12.054.

[8] Xie T, Rousseau IA. Facile tailoring of thermal transition temperatures of epoxy shape memory polymers. Polymer. 2009;50(8):1852-6. https://doi.org/10.1016/j.polymer.2009.02.035.

[9] Rousseau IA, Ounaies Z, Xie T, Li J. Shape memory epoxy: a systematic study of their performance. In: Behavior and mechanics of multifunctional materials and composites. 2009.

[10] Leng J, Xie F, Wu X, Liu Y. Effect of the $\gamma$-radiation on the properties of epoxy-based shape memory polymers. J Intell Mater Syst Struct. 2013;25(10):1256-63. https://doi.org/10.1177/1045389x13504474.

[11] Xie F, Liu L, Gong X, Huang L, Leng J, Liu Y. Effects of accelerated aging on thermal, mechanical and shape memory properties of cyanate-based shape memory polymer: I vacuum ultraviolet radiation. Polym Degrad Stabil. 2017;138:91-7. https://doi.org/10.1016/j.polymdegradstab.2017.03.001.

[12] Tandon GP, Goecke K, Cable K, Baur J. Durability assessment of styrene- and epoxy-based shapememory polymer resins. J Intell Mater Syst Struct. 2009;20(17):2127-43. https://doi.org/10.1177/ 1045389x09348255.

[13] Yao Y, Wei H, Wang J, Lu H, Leng J, Hui D. Fabrication of hybrid membrane of electrospun polycaprolactone and polyethylene oxide with shape memory property. Compos Part B Eng. 2015;83:264-9. https://doi.org/10.1016/j.compositesb.2015.08.060.

[14] Wei H, Wan X, Liu Y, Leng J. 4D printing of shape memory polymers: research status and application prospects. Sci Sin Technol. 2017; . https://doi.org/10.1360/n092017-00156.

[15] Leng JS, Lan X, Liu YJ, Du SY. Electroactive thermoset shape memory polymer nanocomposite filled with nanocarbon powders. Smart Mater Struct. 2009;18(7):074003. https://doi.org/10.1088/0964-1726/ 18/7/074003.

[16] Lan X, Liu LW, Liu YJ, Leng JS. Thermomechanical and electroactive behavior of a thermosetting styrene-based carbon black shape-memory composite. J Appl Polym Sci. 2018;135(13):45978. https:// doi.org/10.1002/app.45978.

[17] Lan X, Leng JS, Liu YJ, Du SY. Investigate of electrical conductivity of shape-memory polymer filled with carbon black. Adv Mater Res Switz. 2008;47-50:714-7. https://doi.org/10.4028/www.scientific.net/ AMR.47-50.714.

[18] Leng JS, Lv HB, Liu YJ, Du SY. Electroactivate shape-memory polymer filled with nanocarbon particles and short carbon fibers. Appl Phys Lett. 2007;91(14):144105. https://doi.org/10.1063/1.2790497.

[19] Yu K, Westbrook KK, Kao PH, Leng J, Qi HJ. Design considerations for shape memory polymer composites with magnetic particles. J Compos Mater. 2013;47(1):51-63. https://doi.org/10.1177/ 0021998312447647. 
[20] Vialle G, Di Prima M, Hocking E, Gall K, Garmestani H, Sanderson T et al. Remote activation of nanomagnetite reinforced shape memory polymer foam. Smart Materials and Structures. 2009. https:// doi.org/10.1088/0964-1726/18/11/115014.

[21] Rose A, Zhu ZG, Madigan CF, Swager TM, Bulovic V. Sensitivity gains in chemosensing by lasing action in organic polymers. Nature. 2005;434(7035):876-9. https://doi.org/10.1038/nature03438.

[22] Leng JS, Zhang DW, Liu Y, Yu K, Lan X. Study on the activation of styrene-based shape memory polymer by medium-infrared laser light. Appl Phys Lett. 2010;96(11):111905. https://doi.org/10.1063/1. 3353970.

[23] Li W, Liu Y, Leng J. Shape memory polymer nanocomposite with multi-stimuli response and two-way reversible shape memory behavior. RSC Adv. 2014;4(106):61847-54. https://doi.org/10.1039/c4ra10716k.

[24] Li W, Liu Y, Leng J. Selectively actuated multi-shape memory effect of a polymer multicomposite. J Mater Chem A. 2015;3(48):24532-9. https://doi.org/10.1039/c5ta08513f.

[25] Beavers F, Munshi N, Lake M, Maji A, Qassim K, Carpenter B, Rawal S. Design and testing of an elastic memory composite deployment hinge for spacecraft. In: 43rd AIAA/ASME/ASCE/AHS/ASC structures, structural dynamics, and materials conference 2002. https://doi.org/10.2514/6.2002-1452.

[26] Li FF, Liu LW, Lan X, Wang T, Li XY, Chen FL, et al. Modal analyses of deployable truss structures based on shape memory polymer composites. Int J Appl Mech. 2016;8(7):1640009. https://doi.org/10. 1142/S1758825116400093.

[27] Zarek M, Layani M, Cooperstein I, Sachyani E, Cohn D, Magdassi S. 3D printing of shape memory polymers for flexible electronic devices. Adv Mater. 2016;28(22):4449-54. https://doi.org/10.1002/adma. 201503132.

[28] Wei H, Zhang Q, Yao Y, Liu L, Liu Y, Leng J. Direct-write fabrication of 4D active shape-changing structures based on a shape memory polymer and its nanocomposite. ACS Appl Mater Interfaces. 2017;9(1):876-83. https://doi.org/10.1021/acsami.6b12824.

[29] Tobushi H, Okumura K, Hayashi S, Ito N. Thermomechanical constitutive model of shape memory polymer. Mech Mater. 2001;33(10):545-54. https://doi.org/10.1016/S0167-6636(01)00075-8.

[30] Tobushi H, Ito N, Takata K, Hayashi S. Thermomechanical constitutive modeling of polyurethane-series shape memory polymer. Mater Sci Forum. 2000;327-3:343-6. https://doi.org/10.4028/www.scientific.net/ MSF.327-328.343.

[31] Tobushi H, Hashimoto T, Hayashi S, Yamada E. Thermomechanical constitutive modeling in shape memory polymer of polyurethane series. J Intell Mater Syst Struct. 1997;8(8):711-8. https://doi.org/10. 1177/1045389x9700800808.

[32] Lin JR, Chen LW. Shape-memorized crosslinked ester-type polyurethane and its mechanical viscoelastic model. J Appl Polym Sci. 1999;73(7):1305-19. https://doi.org/10.1002/(Sici)10974628(19990815)73:7<1305::Aid-App24>3.0.Co;2-5.

[33] Morshedian J, Khonakdar HA, Rasouli S. Modeling of shape memory induction and recovery in heat-shrinkable polymers. Macromol Theory Simul. 2005;14(7):428-34. https://doi.org/10.1002/mats. 200400108.

[34] Khonakdar HA, Jafari SH, Rasouli S, Morshedian J, Abedini H. Investigation and modeling of temperature dependence recovery behavior of shape-memory crosslinked polyethylene. Macromol Theory Simul. 2007;16(1):43-52. https://doi.org/10.1002/mats.200600041.

[35] Diani J, Liu Y, Gall K. Finite strain 3D thermoviscoelastic constitutive model for shape memory polymers. Polym Eng Sci. 2006;46(4):486-92. https://doi.org/10.1002/pen.20497.

[36] Nguyen T, Jerryqi H, Castro F, Long K. A thermoviscoelastic model for amorphous shape memory polymers: incorporating structural and stress relaxation. J Mech Phys Solids. 2008;56(9):2792-814. https:// doi.org/10.1016/j.jmps.2008.04.007.

[37] Srivastava V, Chester SA, Ames NM, Anand L. A thermo-mechanically-coupled large-deformation theory for amorphous polymers in a temperature range which spans their glass transition. Int J Plast. 2010;26(8):1138-82. https://doi.org/10.1016/j.ijplas.2010.01.004.

[38] Srivastava V, Chester SA, Anand L. Thermally actuated shape-memory polymers: experiments, theory, and numerical simulations. J Mech Phys Solids. 2010;58(8):1100-24. https://doi.org/10.1016/j.jmps.2010. 04.004 .

[39] Yu K, McClung AJW, Tandon GP, Baur JW, Jerry Qi H. A thermomechanical constitutive model for an epoxy based shape memory polymer and its parameter identifications. Mech Time Depend Mater. 2014;18(2):453-74. https://doi.org/10.1007/s11043-014-9237-5.

[40] Yu K, Li H, McClung AJ, Tandon GP, Baur JW, Qi HJ. Cyclic behaviors of amorphous shape memory polymers. Soft Matter. 2016;12(13):3234-45. https://doi.org/10.1039/c5sm02781k. 
[41] Gu JP, Sun HY, Fang CQ. A finite deformation constitutive model for thermally activated amorphous shape memory polymers. J Intell Mater Syst Struct. 2015;26(12):1530-8. https://doi.org/10.1177/ $1045389 x 14544147$.

[42] Gu JP, Leng JS, Sun HY. A constitutive model for amorphous shape memory polymers based on thermodynamics with internal state variables. Mecha Mater. 2017;111:1-14. https://doi.org/10.1016/j.mechmat. 2017.04.008.

[43] Fang CQ, Leng JS, Sun HY, Gu JP. A multi-branch thermoviscoelastic model based on fractional derivatives for free recovery behaviors of shape memory polymers. Mech Mater. 2018;120:34-42. https://doi. org/10.1016/j.mechmat.2018.03.002.

[44] Zeng H, Leng JS, Gu JP, Yin CX, Sun HY. Modeling the strain rate-, hold time-, and temperature-dependent cyclic behaviors of amorphous shape memory polymers. Smart Mater Struct. 2018;27(7):075050. https://doi.org/10.1088/1361-665X/aaca50.

[45] Zeng H, Leng JS, Gu JP, Sun HY. A thermoviscoelastic model incorporated with uncoupled structural and stress relaxation mechanisms for amorphous shape memory polymers. Mech Mater. 2018;124:18-25. https://doi.org/10.1016/j.mechmat.2018.05.010.

[46] Liu Y, Gall K, Dunn ML, Greenberg AR, Diani J. Thermomechanics of shape memory polymers: uniaxial experiments and constitutive modeling. Int J Plast. 2006;22(2):279-313. https://doi.org/10.1016/j.ijplas. 2005.03.004.

[47] Chen Y-C, Lagoudas DC. A constitutive theory for shape memory polymers. Part I. J Mech Phys Solids. 2008;56(5):1752-65. https://doi.org/10.1016/j.jmps.2007.12.005.

[48] Chen Y-C, Lagoudas DC. A constitutive theory for shape memory polymers. Part II. J Mech Phys Solids. 2008;56(5):1766-78. https://doi.org/10.1016/j.jmps.2007.12.004.

[49] Wang ZD, Li DF, Xiong ZY, Chang RN. Modeling thermomechanical behaviors of shape memory polymer. J Appl Polym Sci. 2009;113(1):651-6. https://doi.org/10.1002/app.29656.

[50] Reese S, Böl M, Christ D. Finite element-based multi-phase modelling of shape memory polymer stents. Comput Methods Appl Mech Eng. 2010;199(21-22):1276-86. https://doi.org/10.1016/j.cma.2009.08.014.

[51] Volk BL, Lagoudas DC, Maitland DJ. Characterizing and modeling the free recovery and constrained recovery behavior of a polyurethane shape memory polymer. Smart Mater Struct. 2011;20(9):9400419400418. https://doi.org/10.1088/0964-1726/20/9/094004.

[52] Volk BL, Lagoudas DC, Chen Y-C, Whitley KS. Analysis of the finite deformation response of shape memory polymers: I. Thermomechanical characterization. Smart Mater Struct. 2010. https://doi.org/10. 1088/0964-1726/19/7/075005

[53] Volk BL, Lagoudas DC, Chen Y-C. Analysis of the finite deformation response of shape memory polymers: II. $1 \mathrm{D}$ calibration and numerical implementation of a finite deformation, thermoelastic model. Smart Mater Struct. 2010. https://doi.org/10.1088/0964-1726/19/7/075006

[54] Volk BL, Dapino MJ, Lagoudas DC, Ounaies Z, Chen Y-C. Thermomechanical characterization of the nonlinear rate-dependent response of shape memory polymers. Behavior and mechanics of multifunctional and composite materials. 2008.

[55] Gilormini P, Diani J. On modeling shape memory polymers as thermoelastic two-phase composite materials. Comptes Rendus Mécanique. 2012;340(4-5):338-48. https://doi.org/10.1016/j.crme.2012.02.016.

[56] Yang Q, Li G. Temperature and rate dependent thermomechanical modeling of shape memory polymers with physics based phase evolution law. Int J Plast. 2016;80:168-86. https://doi.org/10.1016/j.ijplas. 2015.09.005.

[57] Pan Z, Zhou Y, Zhang N, Liu Z. A modified phase-based constitutive model for shape memory polymers. Polym Int. 2018;67(12):1677-83. https://doi.org/10.1002/pi.5698.

[58] Lu H, Wang X, Yao Y, Fu YQ. A 'frozen volume' transition model and working mechanism for the shape memory effect in amorphous polymers. Smart Mater Struct. 2018. https://doi.org/10.1088/1361-665X/ aab8af

[59] Qi HJ, Nguyen TD, Castro F, Yakacki CM, Shandas R. Finite deformation thermo-mechanical behavior of thermally induced shape memory polymers. J Mech Phys Solids. 2008;56(5):1730-51. https://doi.org/ 10.1016/j.jmps.2007.12.002.

[60] Baghani M, Naghdabadi R, Arghavani J, Sohrabpour S. A thermodynamically-consistent 3D constitutive model for shape memory polymers. Int J Plast. 2012;35:13-30. https://doi.org/10.1016/j.ijplas.2012.01. 007.

[61] Kim JH, Kang TJ, Yu W-R. Thermo-mechanical constitutive modeling of shape memory polyurethanes using a phenomenological approach. Int J Plast. 2010;26(2):204-18. https://doi.org/10.1016/j.ijplas.2009. 06.006 . 
[62] Guo X, Liu L, Zhou B, Liu Y, Leng J. Constitutive model for shape memory polymer based on the viscoelasticity and phase transition theories. J Intell Mater Syst Struct. 2015;27(3):314-23. https://doi. org/10.1177/1045389x15571380.

[63] Guo XG, Liu LW, Zhou B, Liu YJ, Leng JS. Constitutive model for shape memory polymer based on the viscoelasticity and phase transition theories. J Intell Mater Syst Struct. 2016;27(3):314-23. https:// doi.org/10.1177/1045389x15571380.

[64] Park H, Harrison P, Guo ZY, Lee MG, Yu WR. Three-dimensional constitutive model for shape memory polymers using multiplicative decomposition of the deformation gradient and shape memory strains. Mech Mater. 2016;93:43-62. https://doi.org/10.1016/j.mechmat.2015.10.014.

[65] Bhattacharyya A. Isothermal mechanical response of shape memory polymer (SMP)-based hybrid models and SMP-composites. J Mech Behav Mater. 2004;15:107-34.

[66] Guo JM, Liu JBA, Wang ZQ, He XF, Hu LF, Tong LY, et al. A thermodynamics viscoelastic constitutive model for shape memory polymers. J Alloy Compd. 2017;705:146-55. https://doi.org/10.1016/j.jallcom. 2017.02.142.

[67] Li YX, He YH, Liu ZS. A viscoelastic constitutive model for shape memory polymers based on multiplicative decompositions of the deformation gradient. Int J Plast. 2017;91:300-17. https://doi.org/10. 1016/j.ijplas.2017.04.004

[68] Li YX, Liu ZS. A novel constitutive model of shape memory polymers combining phase transition and viscoelasticity. Polymer. 2018;143:298-308. https://doi.org/10.1016/j.polymer.2018.04.026.

[69] Pan'kov AA. A self-consistent statistical mechanics approach for determining effective elastic properties of composites. Theor Appl Fract Mech. 1999;31(3):157-61. https://doi.org/10.1016/S0167-8442(99)00010-5.

[70] Huang Y, Hu KX, Wei X, Chandra A. A generalized self-consistent mechanics method for compositematerials with multiphase inclusions. J Mech Phys Solids. 1994;42(3):491-504. https://doi.org/10.1016/ 0022-5096(94)90028-0.

[71] Huang Y, Hu KX, Chandra A. A self-consistent mechanics method for solids containing inclusions and a general distribution of cracks. Acta Mech. 1994;105(1-4):69-84. https://doi.org/10.1007/Bf01183943.

[72] Huang Y, Hu KX, Chandra A. A generalized self-consistent mechanics method for microcracked solids. J Mech Phys Solids. 1994;42(8):1273-91. https://doi.org/10.1016/0022-5096(94)90035-3.

[73] Huang Y, Hu KX. A generalized self-consistent mechanics method for solids containing elliptical inclusions. J Appl Mech Trans ASME. 1995;62(3):566-72. https://doi.org/10.1115/1.2895982.

[74] Mori T, Tanaka K. Average stress in matrix and average elastic energy of materials with misfitting inclusions. Acta Metall. 1973;21(5):571-4. https://doi.org/10.1016/0001-6160(73)90064-3.

[75] Gunes IS, Cao F, Jana SC. Effect of thermal expansion on shape memory behavior of polyurethane and its nanocomposites. J Polym Sci Part B Polym Phys. 2008;46(14):1437-49. https://doi.org/10.1002/polb. 21480.

[76] Yang Q-S, He X-Q, Liu X, Leng F-F, Mai Y-W. The effective properties and local aggregation effect of CNT/SMP composites. Compos Part B Eng. 2012;43(1):33-8. https://doi.org/10.1016/j.compositesb. 2011.04.027.

[77] Leng J, Yang Q, Asundi AK, Liu X, Leng F, Ecke W. Effective thermo-mechanical properties and shape memory effect of CNT/SMP composites. In: Second international conference on smart materials and nanotechnology in engineering. 2009.

[78] Zare Y. Determination of polymer-nanoparticles interfacial adhesion and its role in shape memory behavior of shape memory polymer nanocomposites. Int J Adhes Adhes. 2014;54:67-71. https://doi.org/10. 1016/j.ijadhadh.2014.05.004.

[79] Abishera R, Velmurugan R, Gopal KVN. Reversible plasticity shape memory effect in epoxy/CNT nanocomposites - a theoretical study. Compos Sci Technol. 2017;141:145-53. https://doi.org/10.1016/ j.compscitech.2017.01.020.

[80] Hassanzadeh-Aghdam MK, Mahmoodi MJ. Micromechanics-based characterization of elastic properties of shape memory polymer nanocomposites containing $\mathrm{SiO}_{2}$ nanoparticles. J Intell Mater Syst Struct. 2018;29(11):2392-405. https://doi.org/10.1177/1045389x18770862.

[81] Abishera R, Velmurugan R, Nagendra Gopal KV. Free, partial, and fully constrained recovery analysis of cold-programmed shape memory epoxy/carbon nanotube nanocomposites: experiments and predictions. J Intell Mater Syst Struct. 2018;29(10):2164-76. https://doi.org/10.1177/1045389x18758187.

[82] Jarali CS, Madhusudan M, Vidyashankar S, Raja S. A new micromechanics approach to the application of Eshelby's equivalent inclusion method in three phase composites with shape memory polymer matrix. Compos Part B Eng. 2018;152:17-30. https://doi.org/10.1016/j.compositesb.2018.06.028. 
[83] Taherzadeh M, Baghani M, Baniassadi M, Abrinia K, Safdari M. Modeling and homogenization of shape memory polymer nanocomposites. Compos Part B Eng. 2016;91:36-43. https://doi.org/10.1016/j. compositesb.2015.12.044.

[84] Pan ZZ, Huang R, Liu ZS. Prediction of the thermomechanical behavior of particle reinforced shape memory polymers. Polym Compos. 2019;40(1):353-63. https://doi.org/10.1002/pc.24658.

[85] Talreja R. Assessment of the fundamentals of failure theories for composite materials. Compos Sci Technol. 2014;105:190-201. https://doi.org/10.1016/j.compscitech.2014.10.014.

[86] Zhuang L, Talreja R. Effects of voids on postbuckling delamination growth in unidirectional composites. Int J Solids Struct. 2014;51(5):936-44. https://doi.org/10.1016/j.ijsolstr.2013.11.021.

[87] Lan X, Liu L, Liu Y, Leng J, Du S. Post microbuckling mechanics of fibre-reinforced shape-memory polymers undergoing flexure deformation. Mech Mater. 2014;72:46-60. https://doi.org/10.1016/j.mechmat. 2013.05.012.

[88] Agoras M, Lopez-Pamies O, Ponte Castañeda P. A general hyperelastic model for incompressible fiberreinforced elastomers. J Mech Phys Solids. 2009;57(2):268-86. https://doi.org/10.1016/j.jmps.2008.10. 014.

[89] Lopez-Pamies O, Idiart MI. Fiber-reinforced hyperelastic solids: a realizable homogenization constitutive theory. J Eng Math. 2010;68(1):57-83. https://doi.org/10.1007/s10665-009-9359-y.

[90] López Jiménez F. On the isotropy of randomly generated representative volume elements for fiberreinforced elastomers. Compos Part B Eng. 2016;87:33-9. https://doi.org/10.1016/j.compositesb.2015. 10.014 .

[91] Jimenez FL, Pellegrino S. Folding of fiber composites with a hyperelastic matrix. Int J Solids Struct. 2012;49(3-4):395-407. https://doi.org/10.1016/j.ijsolstr.2011.09.010.

[92] Lignon E, Le Tallec P, Triantafyllidis N. Onset of failure in a fiber reinforced elastomer under constrained bending. Int J Solids Struct. 2013;50(2):279-87. https://doi.org/10.1016/j.ijsolstr.2012.07.022.

[93] Francis W, Lake M, Schultz M, Campbell D, Dunn M, Qi HJ. Elastic memory composite microbuckling mechanics: closed-form model with empirical correlation. In: 48th AIAA/ASME/ASCE/AHS/ASC structures, structural dynamics, and materials conference. 2007. https://doi.org/10.2514/6.2007-2164

[94] Wang ZD, Li ZF, Xiong ZY, Wang LY. Theoretical studies on microbuckling mode of elastic memory composites. Acta Mech Solida Sin. 2010;23(1):20-8.

[95] Zhang J, Dui G, Liang X. Revisiting the micro-buckling of carbon fibers in elastic memory composite plates under pure bending. Int J Mech Sci. 2018;136:339-48. https://doi.org/10.1016/j.ijmecsci.2017.12. 018.

[96] MIL-STD-1540C. Test Requirements for Launch, Upper-Stage, and Space Vehicles 1994.

[97] Barrett R, Francis W, Abrahamson E, Lake M, Scherbarth M. Qualification of elastic memory composite hinges for spaceflight applications. In: 47th AIAA/ASME/ASCE/AHS/ASC structures, structural dynamics, and materials conference $<$ BR $>14$ th AIAA/ASME/AHS adaptive structures conference. 2006.

[98] Francis W, Lake M, Mallick K, Freebury G, Maji A. Development and testing of a hinge/actuator using elastic memory composites. In: 44th AIAA/ASME/ASCE/AHS/ASC structures, structural dynamics, and materials conference. 2003. https://doi.org/10.2514/6.2003-1496

[99] Ounaies Z, Lan X, Li J, Wang X, Lu H, Liu Y et al. Shape recovery performances of a deployable hinge fabricated by fiber-reinforced shape-memory polymer. In: Behavior and mechanics of multifunctional materials and composites. 2009.

[100] Lan X, Liu YJ, Lv HB, Wang XH, Leng JS, Du SY. Fiber reinforced shape-memory polymer composite and its application in a deployable hinge. Smart Mater Struct. 2009;18(2):024002. https://doi.org/10. 1088/0964-1726/18/2/024002.

[101] Campbell D, Lake M, Scherbarth M, Nelson E, Six R. Elastic memory composite material: an enabling technology for future furlable space structures. In: 46th AIAA/ASME/ASCE/AHS/ASC structures, structural dynamics and materials conference. 2005. https://doi.org/10.2514/6.2005-2362

[102] Zhang R, Guo X, Liu Y, Leng J. Theoretical analysis and experiments of a space deployable truss structure. Compos Struct. 2014;112:226-30. https://doi.org/10.1016/j.compstruct.2014.02.018.

[103] Fang H, Shook L, Lin J, Pearson J, Moore J. A Large and high radio frequency deployable reflector. In: 53rd AIAA/ASME/ASCE/AHS/ASC structures, structural dynamics and materials conference $<$ BR $>$ 20th AIAA/ASME/AHS adaptive structures conference $<$ BR $>14$ th AIAA2012

[104] Li FF, Liu LW, Lan X, Zhou XJ, Bian WF, Liu YJ, et al. Preliminary design and analysis of a cubic deployable support structure based on shape memory polymer composite. Int J Smart Nano Mater. 2016;7(2):106-18. https://doi.org/10.1080/19475411.2016.1212948. 
[105] Keller P, Lake M, Codell D, Barrett R, Taylor R, Schultz M. Development of elastic memory composite stiffeners for a flexible precision reflector. In: 47th AIAA/ASME/ASCE/AHS/ASC structures, structural dynamics, and materials conference $<$ BR $>14$ th AIAA/ASME/AHS adaptive structures conference $<$ BR $>$ 7th. 2006. https://doi.org/10.2514/6.2006-2179

[106] Yang P. Research on the structure of space deployable antenna based on shape memory polymer composite. Dissertation for the Master Degree in Engineering, School of Astronautic, Harbin Institute of Technology

[107] Chen Q, Yao Z, Hou Y, Fang H. Design and testing of a space deployable mechanism. In: 4th AIAA spacecraft structures conference. 2017.

[108] Rakow A, Hedin K, Anthony B. Development of high specific power solar arrays with shape memory polymer hinge lines. In: AIAA spacecraft structures conference. 2018.

[109] Liu TZ, Liu LW, Yu M, Li QF, Zeng CJ, Lan X, et al. Integrative hinge based on shape memory polymer composites: material, design, properties and application. Compos Struct. 2018;206:164-76. https://doi. org/10.1016/j.compstruct.2018.08.041.

[110] https://www.nasa.gov/mission_pages/station/research/experiments/explorer/Investigation.html?\# id $=1876$.

[111] https://www.ted.com/talks/skylar_tibbits_the_emergence_of_4d_printing?language=zh-cn.

[112] Tibbits S. 4D printing: multi-material shape change. Archit Des. 2014;84(1):116-21. https://doi.org/10. $1002 /$ ad.1710.

[113] Momeni F, Hassani NSMM, Liu X, Ni J. A review of 4D printing. Mater Des. 2017;122:42-79. https:// doi.org/10.1016/j.matdes.2017.02.068.

[114] Yu K, Dunn ML, Qi HJ. Digital manufacture of shape changing components. Extreme Mech Lett. 2015;4:9-17. https://doi.org/10.1016/j.eml.2015.07.005.

[115] Wu JT, Yuan C, Ding Z, Isakov M, Mao YQ, Wang TJ, et al. Multi-shape active composites by 3D printing of digital shape memory polymers. Sci Rep. 2016;6:24224. https://doi.org/10.1038/srep24224.

[116] Bodaghi M, Damanpack AR, Liao WH. Triple shape memory polymers by 4D printing. Smart Mater Struct. 2018;27(6):065010. https://doi.org/10.1088/1361-665X/aabc2a.

[117] Zhao TT, Yu R, Li XP, Cheng B, Zhang Y, Yang X, et al. 4D printing of shape memory polyurethane via stereolithography. Eur Polym J. 2018;101:120-6. https://doi.org/10.1016/j.eurpolymj.2018.02.021.

[118] Ge Q, Dunn CK, Qi HJ, Dunn ML. Active origami by 4D printing. Smart Mater Struct. 2014;23(9):094007. https://doi.org/10.1088/0964-1726/23/9/094007.

[119] Mao YQ, Yu K, Isakov MS, Wu JT, Dunn ML, Qi HJ. Sequential self-folding structures by 3D printed digital shape memory polymers. Sci Rep. 2015;5:13616. https://doi.org/10.1038/srep13616.

[120] Wagner M, Chen T, Shea K. Large shape transforming 4D auxetic structures. 3D Print Addit Manuf. 2017;4(3):133-41. https://doi.org/10.1089/3dp.2017.0027.

[121] Gladman AS, Matsumoto EA, Nuzzo RG, Mahadevan L, Lewis JA. Biomimetic 4D printing. Nat Mater. 2016;15(4):413. https://doi.org/10.1038/Nmat4544.

[122] Bodaghi M, Damanpack AR, Liao WH. Adaptive metamaterials by functionally graded 4D printing. Mater Des. 2017;135:26-36. https://doi.org/10.1016/j.matdes.2017.08.069.

[123] Zhang Q, Zhang K, Hu GK. Smart three-dimensional lightweight structure triggered from a thin composite sheet via 3D printing technique. Sci Rep. 2016;6:22431. https://doi.org/10.1038/srep22431.

[124] Choong YYC, Maleksaeedi S, Eng H, Wei J, Su PC. 4D printing of high performance shape memory polymer using stereolithography. Mater Des. 2017;126:219-25. https://doi.org/10.1016/j.matdes.2017.04. 049.

[125] Zarek M, Layani M, Cooperstein I, Sachyani E, Cohn D, Magdassi S. 3D printing of shape memory polymers for flexible electronic devices. Adv Mater. 2016;28(22):4449-54. https://doi.org/10.1002/adma. 201503132.

[126] Yang H, Leow WR, Wang T, Wang J, Yu JC, He K, et al. 3D printed photoresponsive devices based on shape memory composites. Adv Mater. 2017;29(33):1701627. https://doi.org/10.1002/adma.201701627.

[127] Zhang W, Zhang FH, Lan X, Leng JS, Wu AS, Bryson TM, et al. Shape memory behavior and recovery force of 4D printed textile functional composites. Compos Sci Technol. 2018;160:224-30. https://doi.org/ 10.1016/j.compscitech.2018.03.037.

[128] Kuang X, Chen KJ, Dunn CK, Wu JT, Li VCF, Qi HJ. 3D printing of highly stretchable, shape-memory, and self-healing elastomer toward novel 4D printing. ACS Appl Mater Interfaces. 2018;10(8):7381-8. https://doi.org/10.1021/acsami.7b18265.

[129] Yang Y, Chen YH, Wei Y, Li YT. 3D printing of shape memory polymer for functional part fabrication. Int J Adv Manuf Technol. 2016;84(9-12):2079-95. https://doi.org/10.1007/s00170-015-7843-2. 
[130] Ge Q, Sakhaei AH, Lee H, Dunn CK, Fang NX, Dunn ML. Multimaterial 4D printing with tailorable shape memory polymers. Sci Rep. 2016;6:31110. https://doi.org/10.1038/srep31110.

[131] Yang Y, Chen YH, Wei Y, Li YT. Novel design and three-dimensional printing of variable stiffness robotic grippers. J Mech Robot. 2016;8(6):061010. https://doi.org/10.1115/1.4033728.

[132] Zarek M, Mansour N, Shapira S, Cohn D. 4D printing of shape memory-based personalized endoluminal medical devices. Macromol Rapid Commun. 2017;38(2):1600628. https://doi.org/10.1002/marc. 201600628.

[133] Miao SD, Zhu W, Castro NJ, Leng JS, Zhang LG. Four-dimensional printing hierarchy scaffolds with highly biocompatible smart polymers for tissue engineering applications. Tissue Eng Part C Methods. 2016;22(10):952-63. https://doi.org/10.1089/ten.tec.2015.0542. 